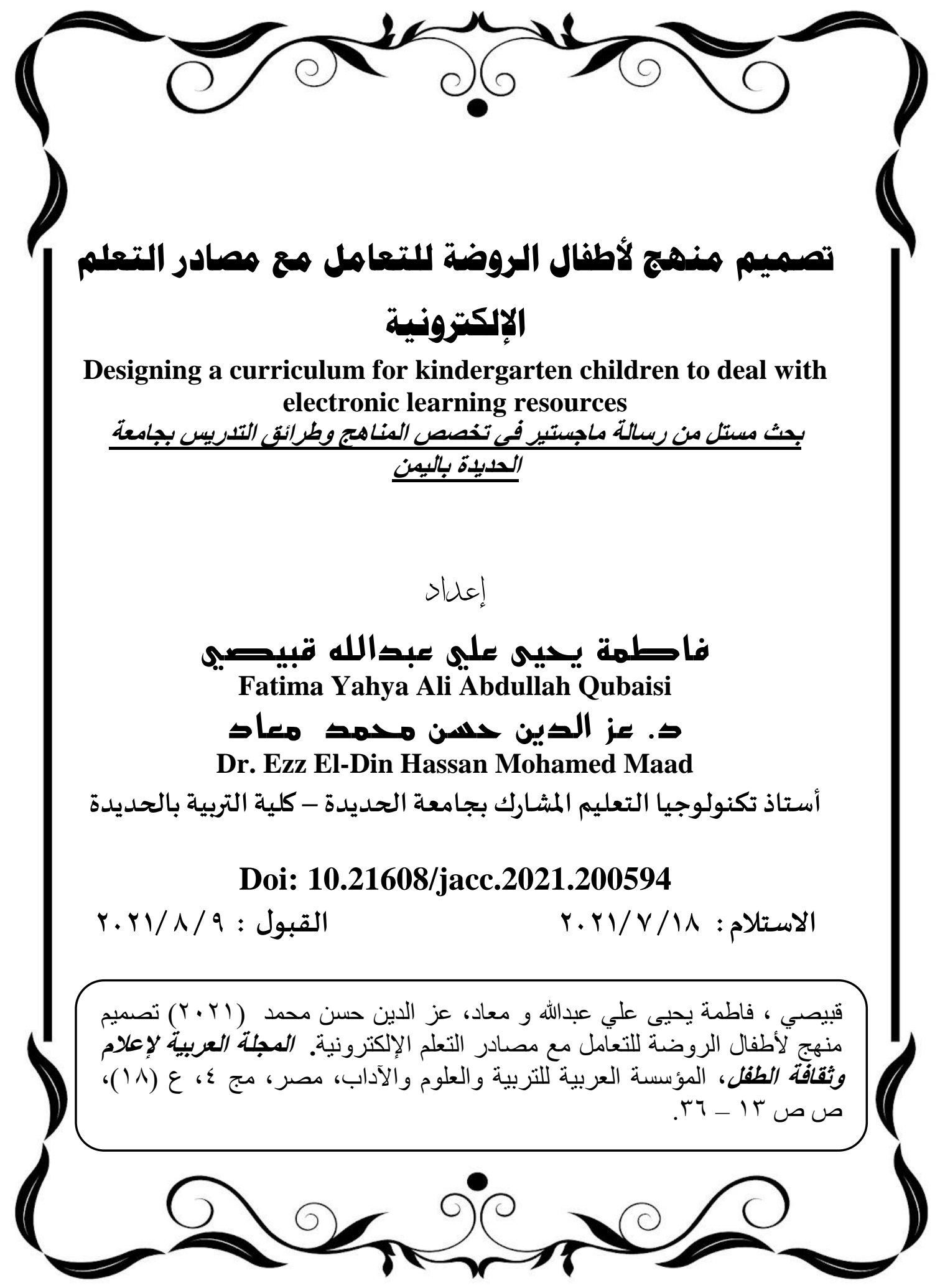




\section{تصميم منهج لأطفال الروضة للتعامل مع مصادر التعلم الإكترونية}

هدف هذا البحث إلى تصميم منهج لأطفال الروضة؛ للتعامل مع مصادر التعلم

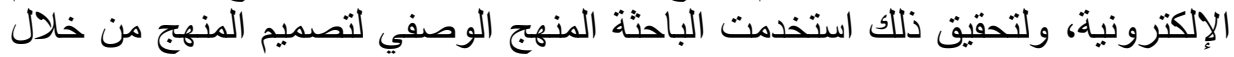

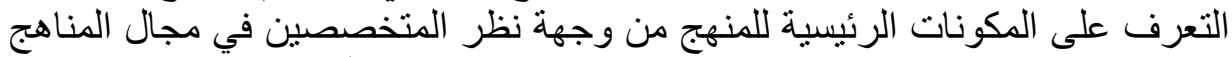

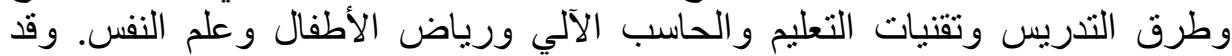

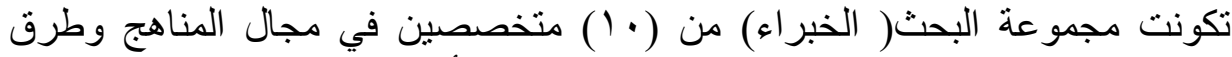

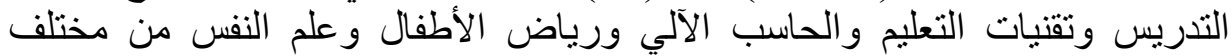

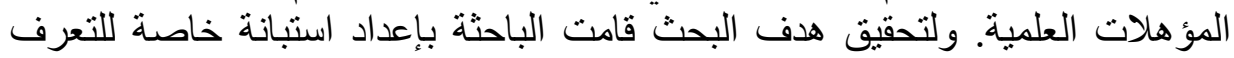

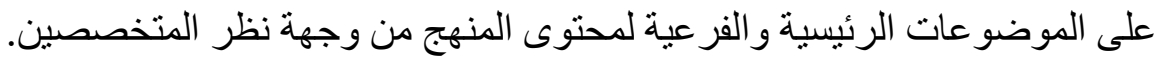
وجاءت النتائج على النحو الآتي:

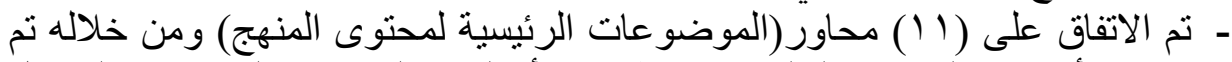

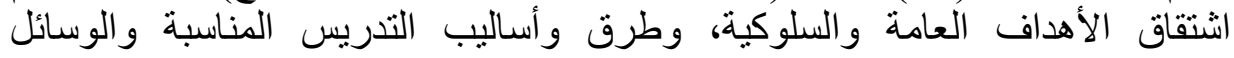
و الأنشطة التعليمية، وطرق والهافي وأساليب التقويم المناسبة.

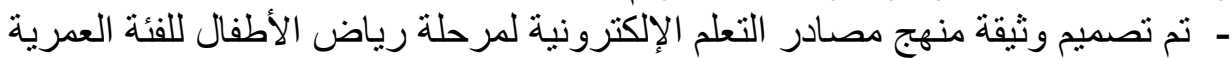

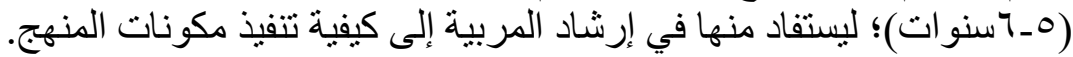

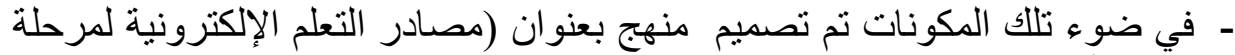

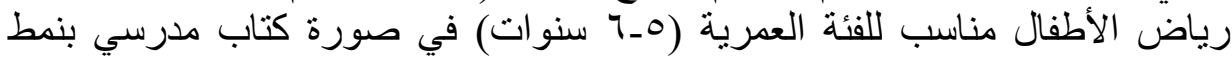

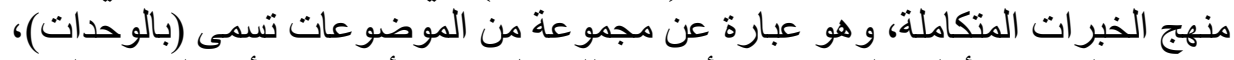

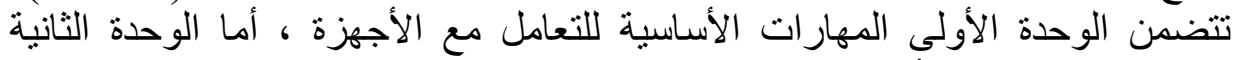

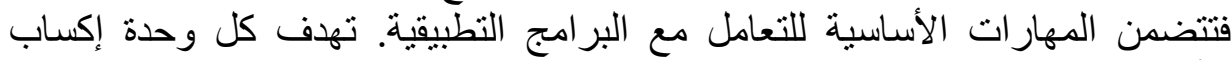

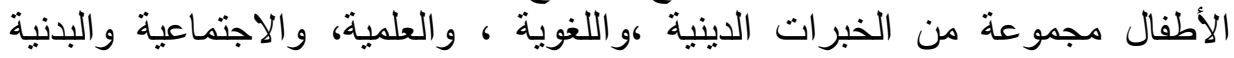

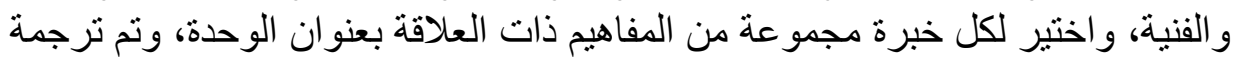

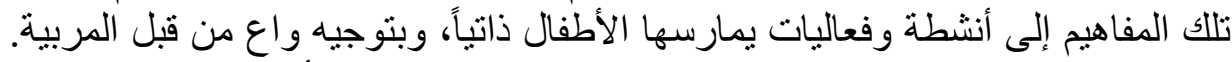

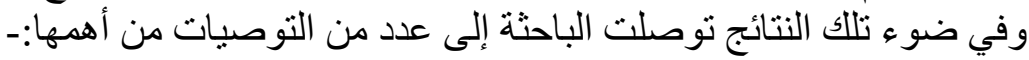

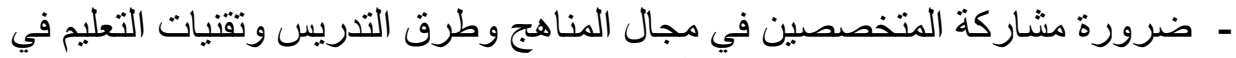

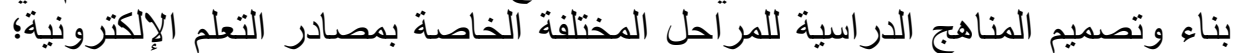
وعدم اقتصار ذلك على المتخصصين في الحاسب الآلي وتقنية المعلومات الخدات.

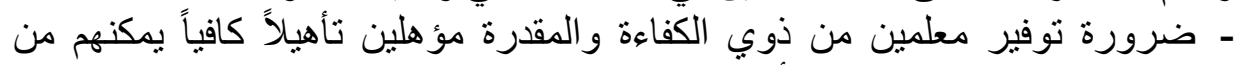
تدريس مفردات المنهج؛ لتحقيق أهدافه على الوجن الوفاءه المطلوب.

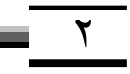




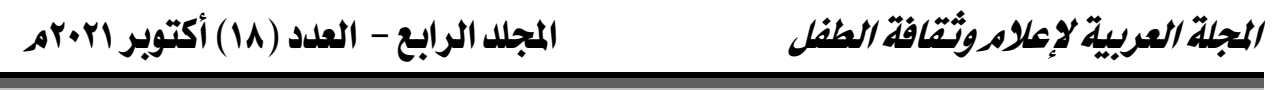

- إجراء التدريبات و التطبيقات العملية اللازمة للمعلمين في حالة عدم توفر الكفاءة

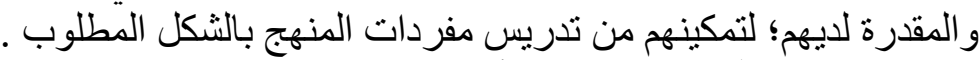
الكلمات المفتاحية: تصميم، منهج أطفال الروضة، دصنية مصادر التعلم الإلكترونية.

\section{Abstract:}

This research aims at designing a curriculum for kindergarten in order to deal with the Source of electronic learning (E-learning). For Achieving this the researcher used descriptive method to design the essential components for the curriculum from specialists point of views. They are specialists in Curriculum, Methods, Educational Techniques, Computer, Kindergarten and Psychology. The research sample consists of (10) specialists in Curriculum, Methods, Teaching Techniques, Computer, Kindergarten and Psychology of different qualifications. The research procedures were summarized in special questionnaire for the headings and sub-headings topics. Those headings include the content of curriculum from specialists point of views. The results were as follows :

- It was agreed on (11) principles (headings and sub-headings for the content of curriculum). The general objectives and behavioral objectives, the appropriate methodologies, teaching aids and activities and appropriate evaluation methods were decided according to these headings.

- A guidance for tutors entitled (The tutor Guidance for Teaching E-Learning sources Curriculum for Kindergarten, between 5-6 years) for guiding tutors on how to implement components of the curriculum.

- According to these components, a curriculum entitled (sources of E-learning for kindergarten appropriate for 5-6 years) in a form of pupils book using intergarted experience approach which is collection of topics called units. Unit one includes the essential skills to deal with the devices the second unit includes essential skills to deal with application programs, each unit aims to enable children group of religious, linguistics scientific, social, physical, 
artistic skills. For each experience group of principles related to the unit title and they were translated to activities to be done by children autonomously and with teacher supervision

On the basis of these outcomes, the researcher found out that :

- Experts in curriculum, methods and Learning techniques should necessarily participate in designing teaching curriculums for different stages and levels related to E- learning sources, not only experts on computer and I.T

- Competent teachers should be available to teach this syllabus in order to achieve the required objectives.

-To carry out the necessary practical training for the the teachers who lack the experience and the capabilities to help them leach properly.

أصبح التعليم ناطق الثورة التكنولوجية وما ينتج عنها من مستحدثات جديدة ومتغيرة

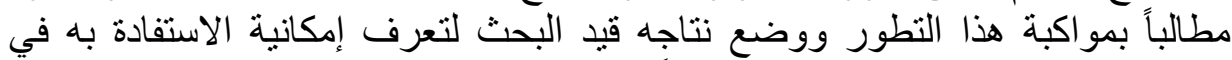

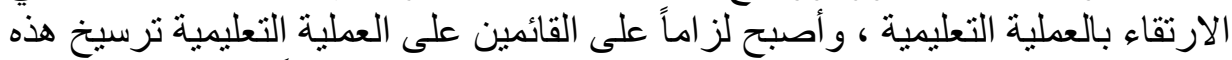

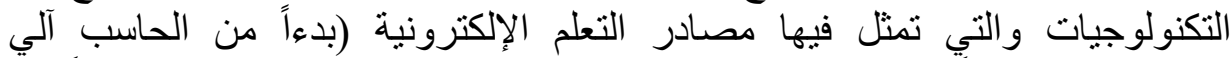

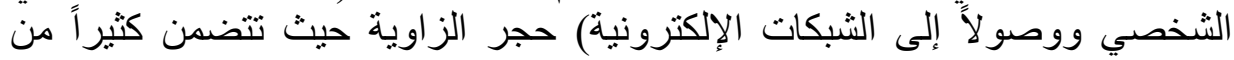

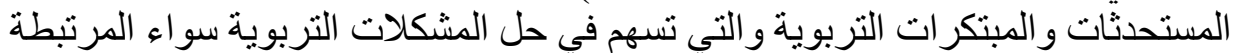

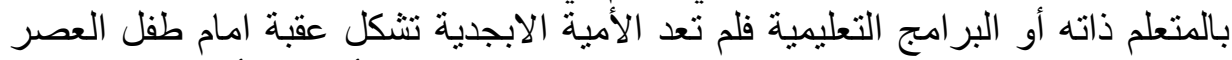

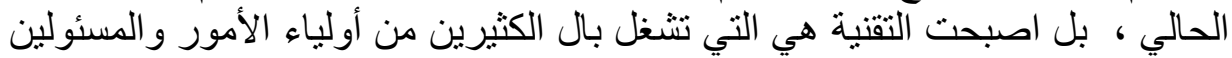

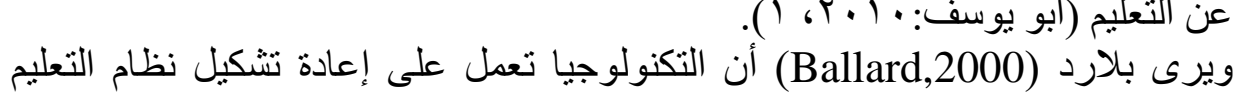

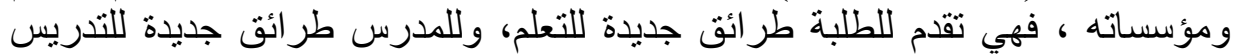

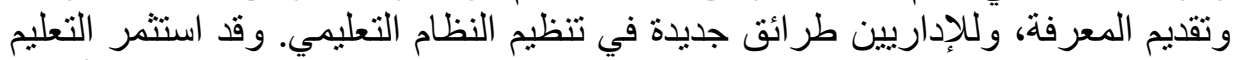

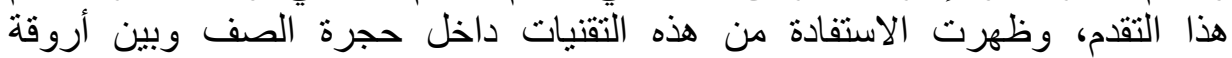

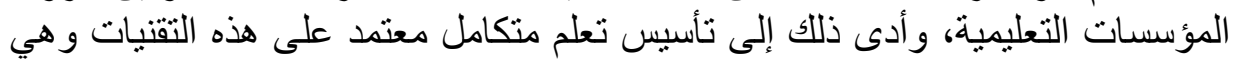
ما بسمى بالتعلم الإلكترونية.

Http://www.abegs .org/fntokhtm 
و هذا ما يؤكده سبندر(Spender:2001,21-33)أن التعلم الإلكترونية هو الجيل القادم

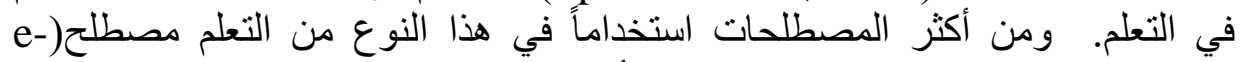
Learning

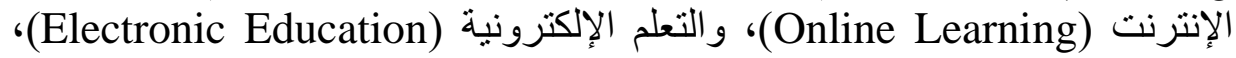

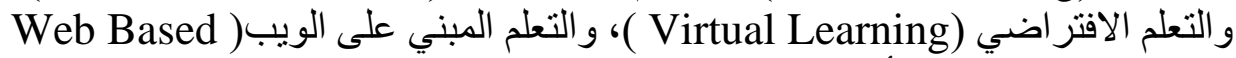
Learning

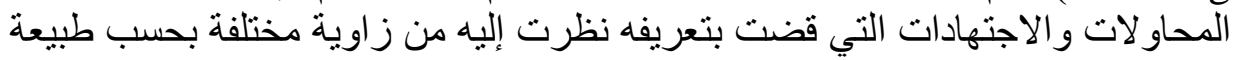

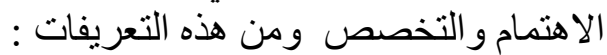

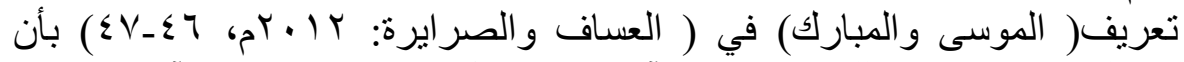

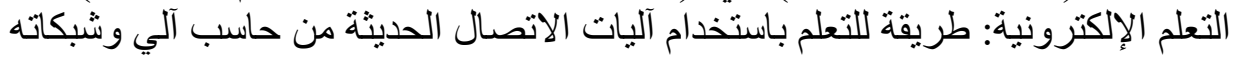

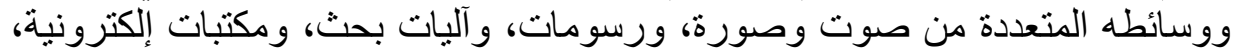

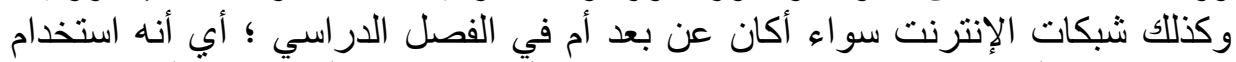

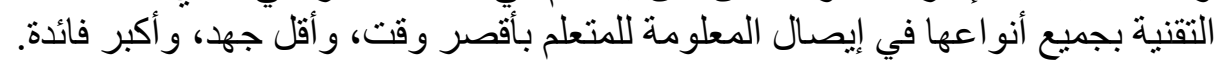

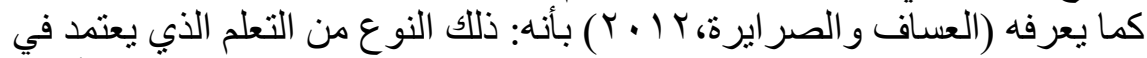

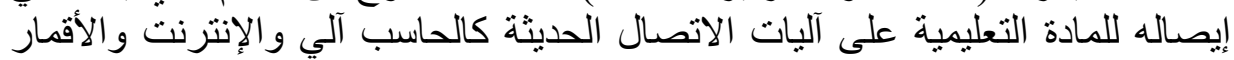

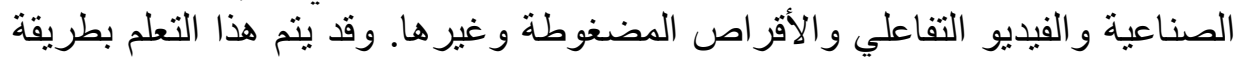

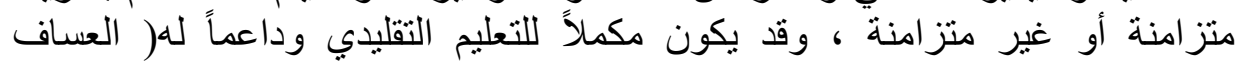

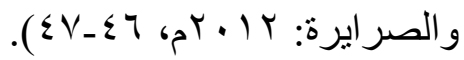

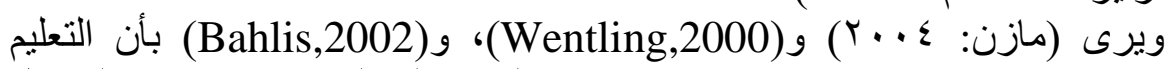

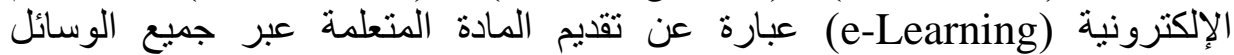

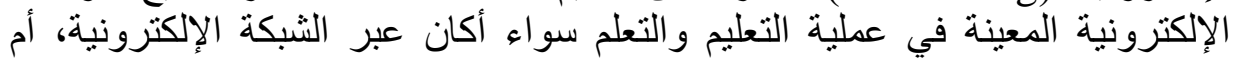

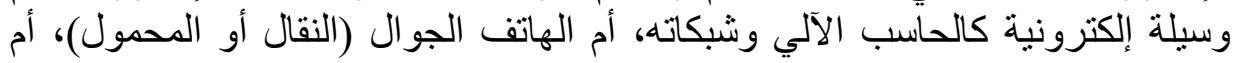
غير ها. و هناك آراء متعددة عن التعليم الإلكترونية ، فيرى (Naber\&Kohlen,2002)

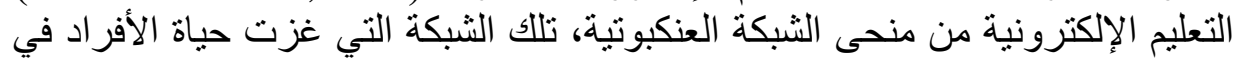

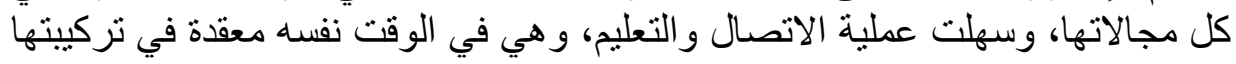

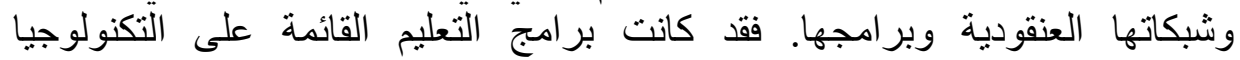
Time ب بسطة بحيث يمكن تقسيمها على الميزان الزمني (Technology Based) (Scale التلفزيونية ، أو الإذاعية وغير هان، ولا تزامني (Asynchronous) مثل : أنشرطة الفيديو و التسجيلات الصونة ، الصوبة وعية 


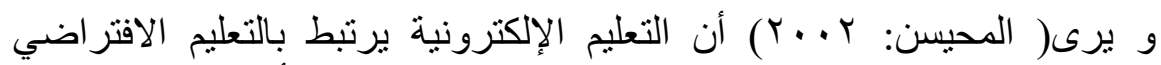

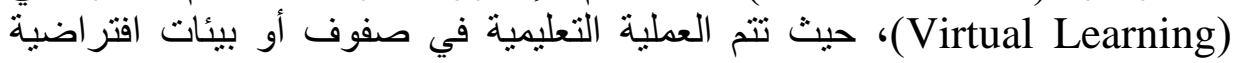
تختلف عن الصفوف التقليدية المعتادة وذلك عن طريق التئ استخدام التقنيات الإلكترونية

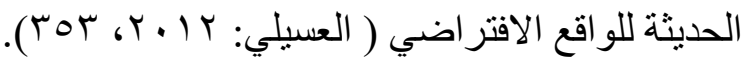

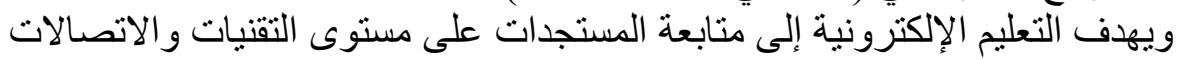

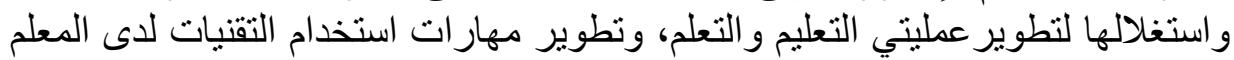

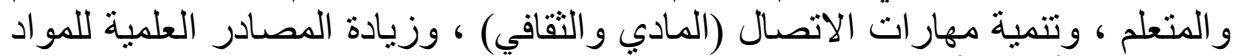

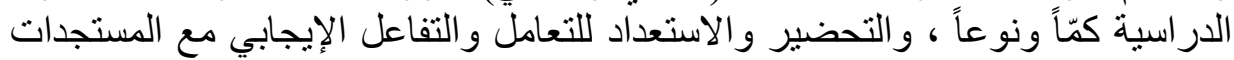

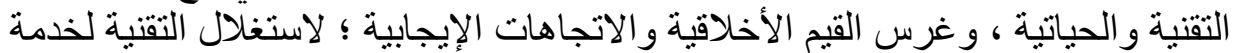

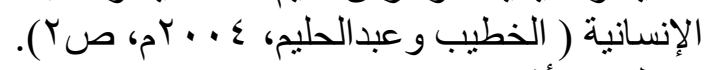

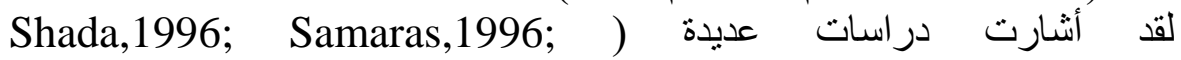
الحيلة Samuelsson,2001; Plowman \& Stephan,2005;

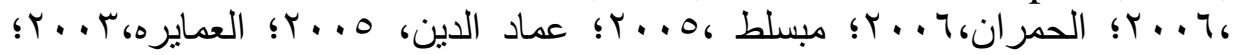

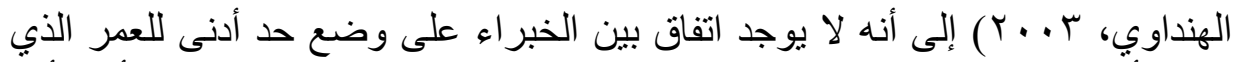

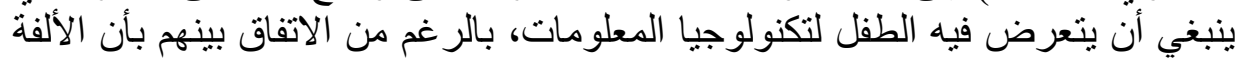

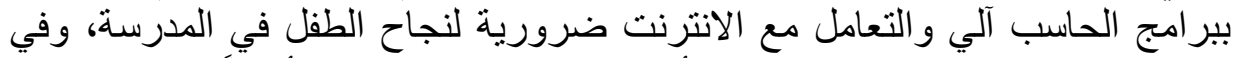

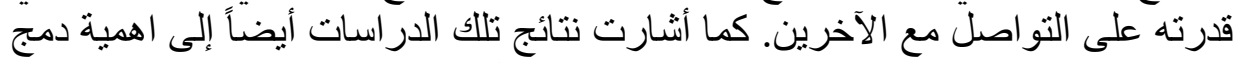

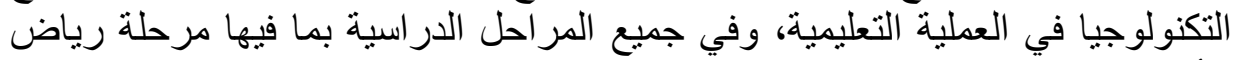

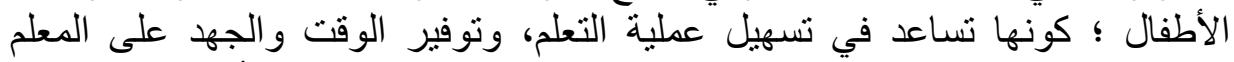

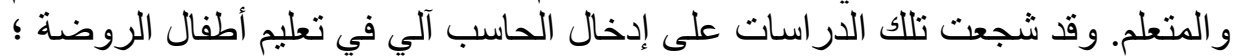

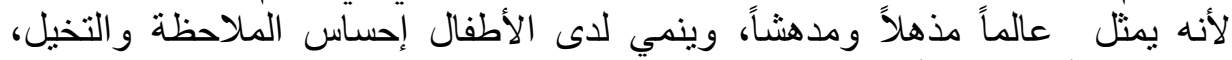

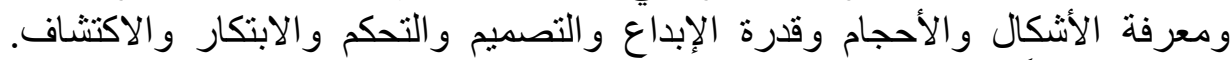

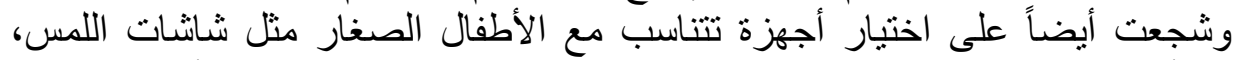

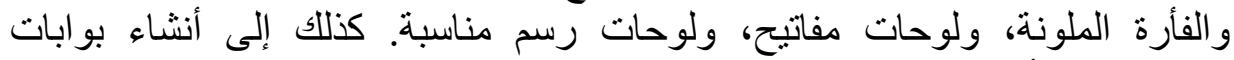

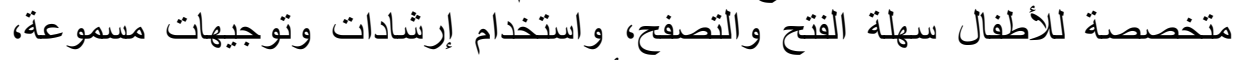

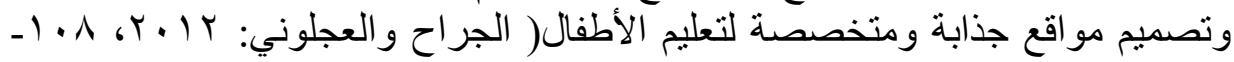

ونظر اً لكون فترة الطفولة تعتبر من أخصب الفترات لاكتساب المفاهيم و المهارات

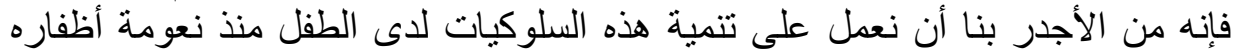

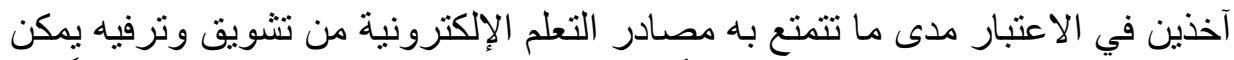

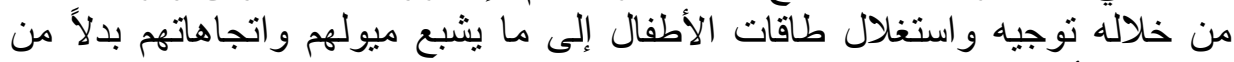

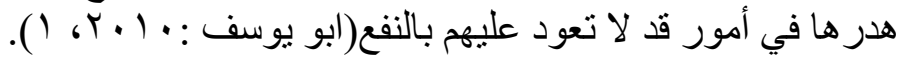


وقد بينت العديد من الدراسات والبحوث التي تناولت آثار توظيف تكنولوجيا

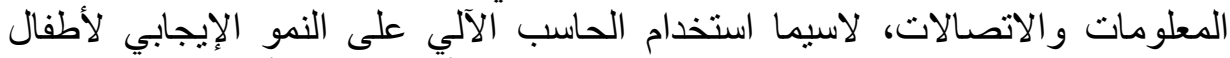

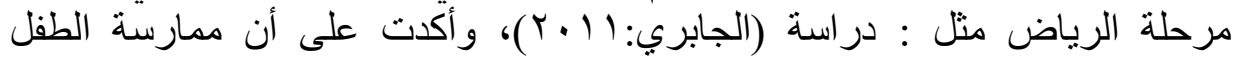

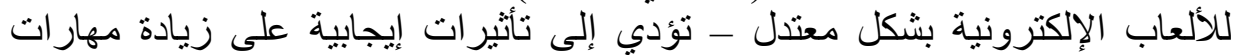

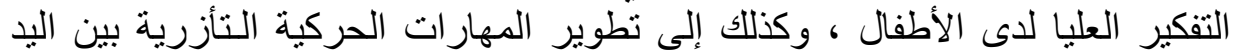

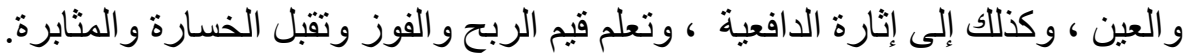

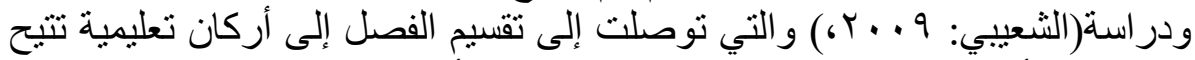

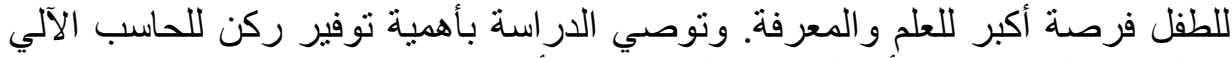

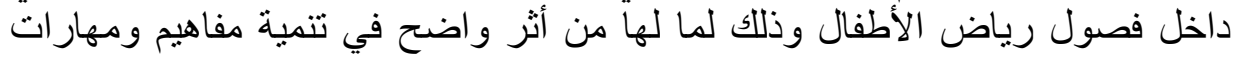

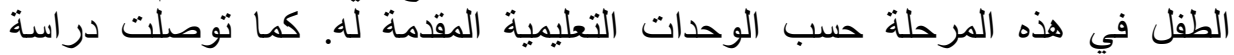

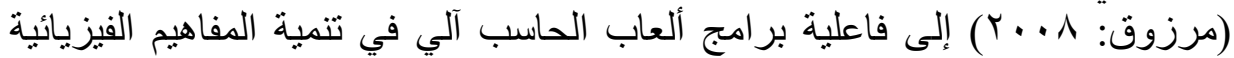

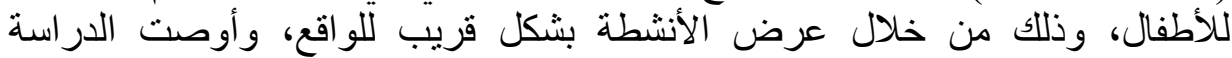

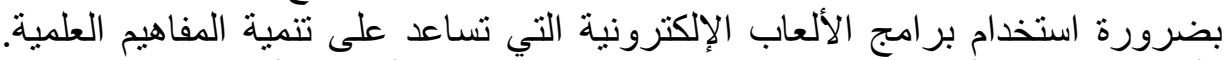

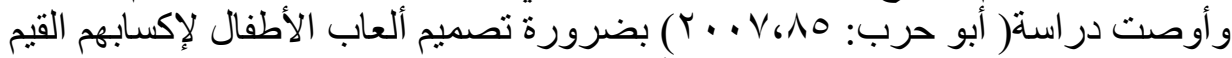

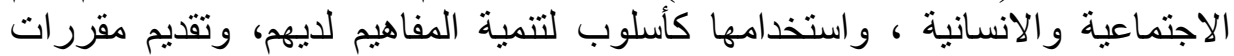

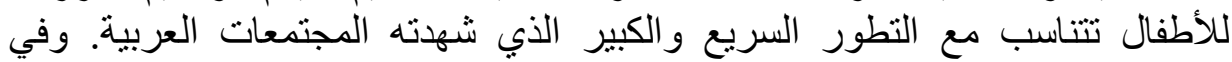

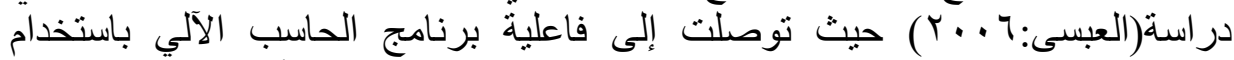

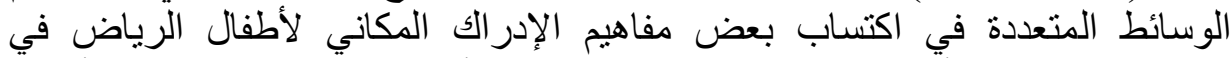

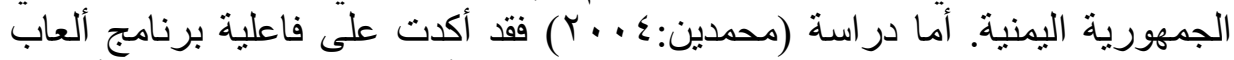

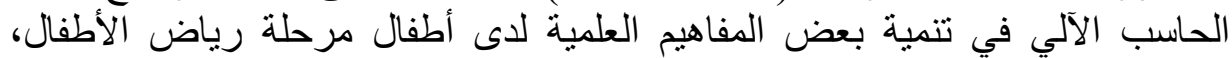

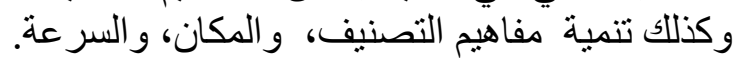

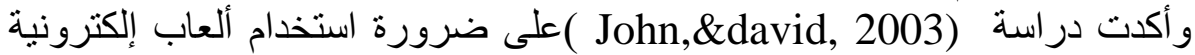

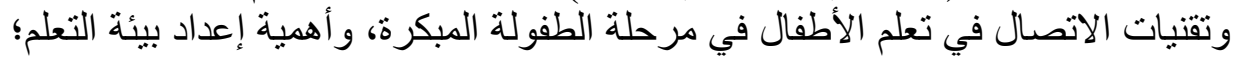

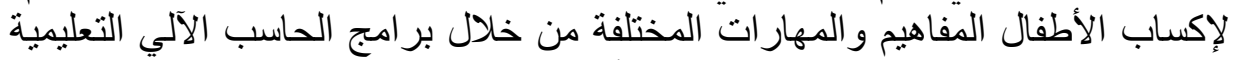

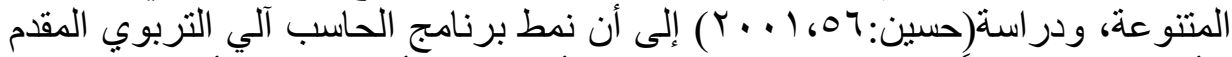

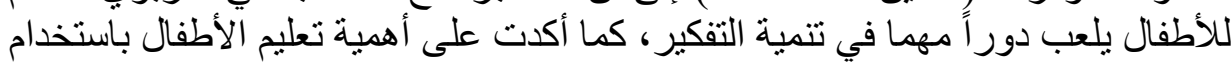

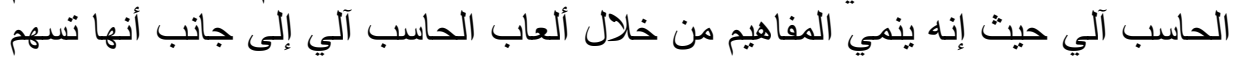

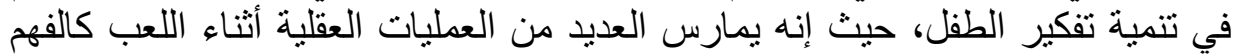

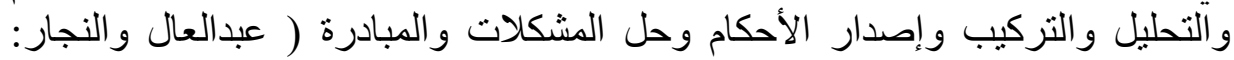

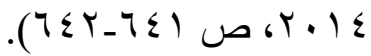


أما دراسـة (Lui-Min,1996) فقد أشتارت إلى أهمية التعليم باستخدام

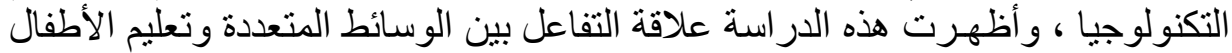

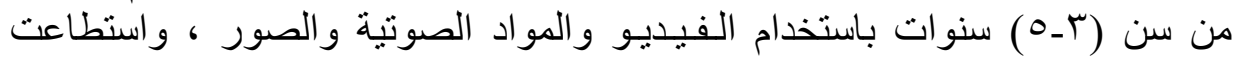

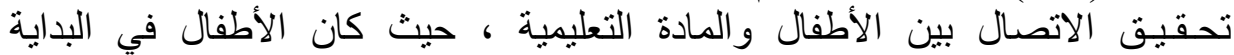

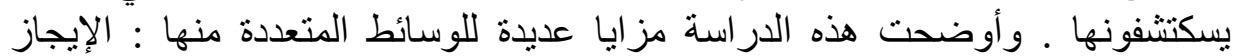
و التلخيص واستخدام الفن كعناصر محبية للطفل. وأثـارت دراسـة (Heimnn,1995) إلى ألى أن استخدام الوسائط المتعددة ســل مـن اكتساب الأطفال القرة على تعليمهم معلومات بيئية، بطريقة فردية في أعمار

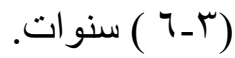

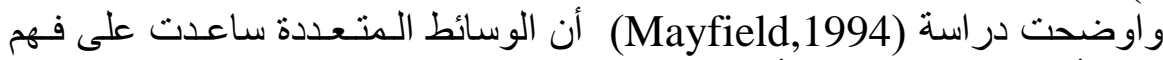
وترميز الأنشطة عند صغار الأطفال ، وبصفة خاصة عند سماع القصان القص القص وساعدتهم

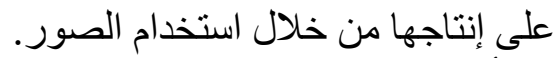

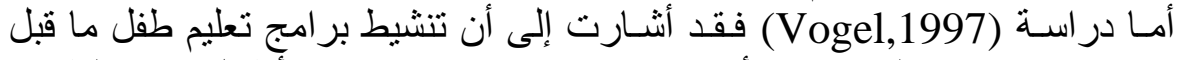

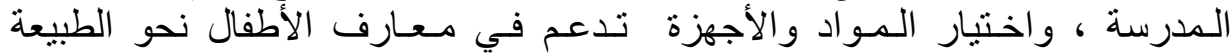

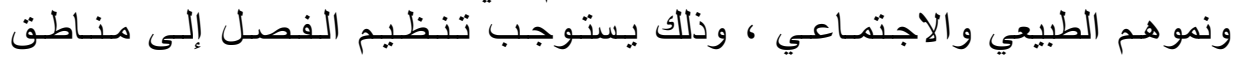

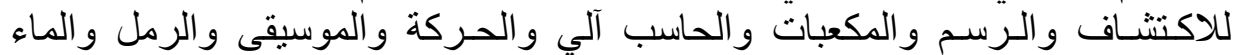

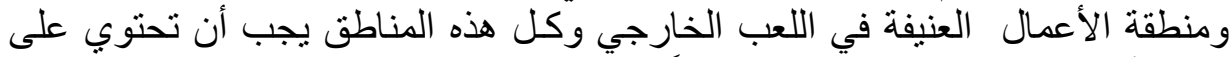

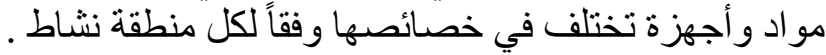

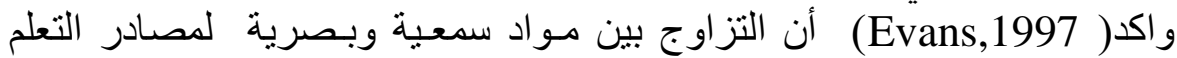

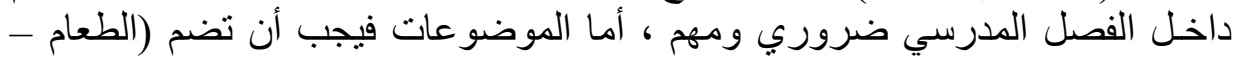

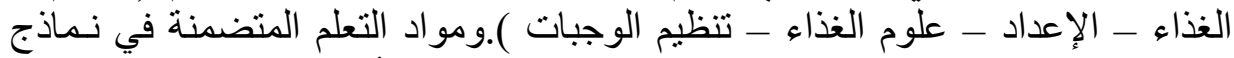

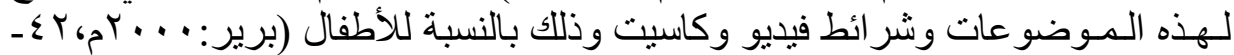

إن إعداد وتصميم وتجريب برنامج الحاسب الآلي قائم على محاكاة القصة التفاعلية

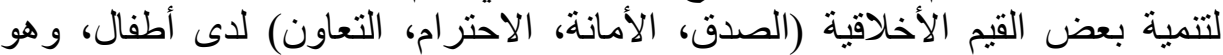

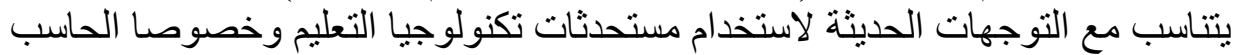

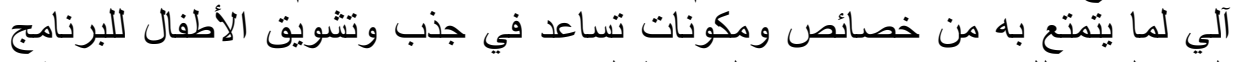

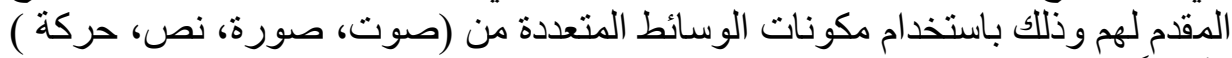

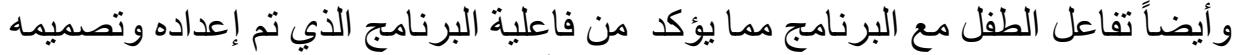

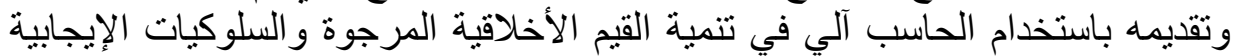

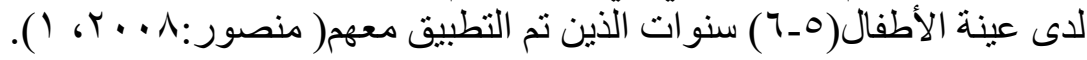




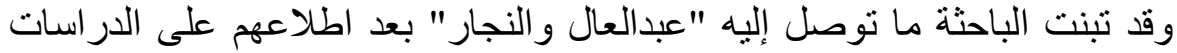

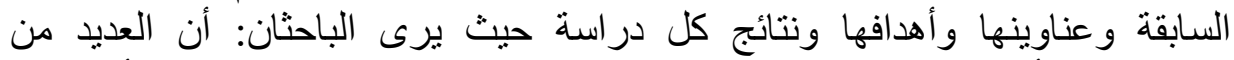

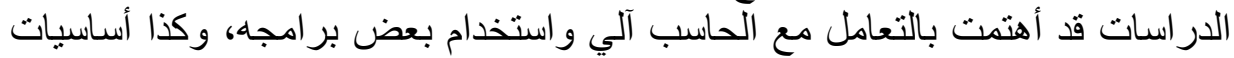

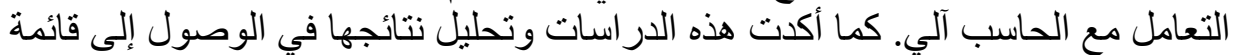

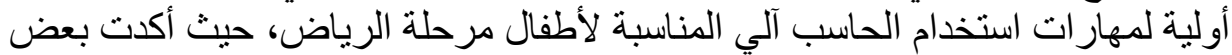

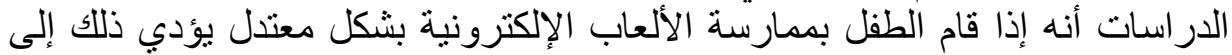

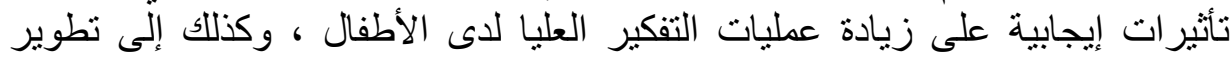

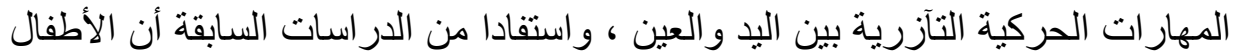

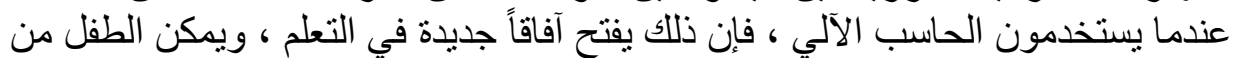

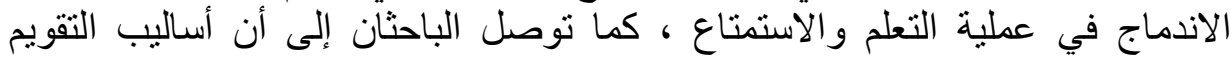

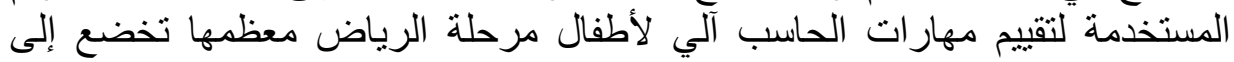

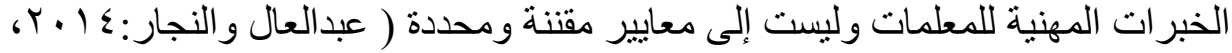
وقد أصبح معروفاً أنه لا يمكن الاستغناء عن الحاسب الآلي في هذا العصر ( القرن

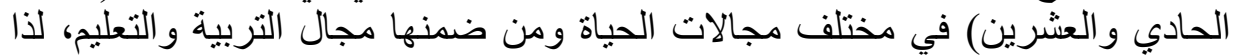

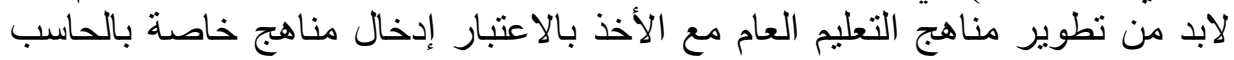

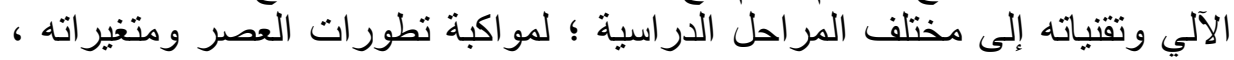

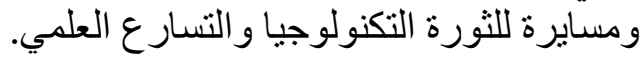

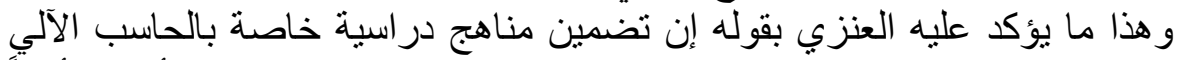

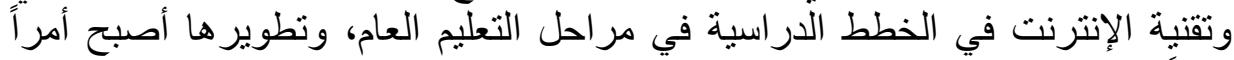

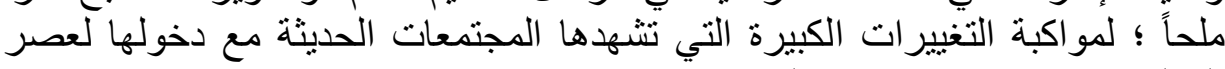

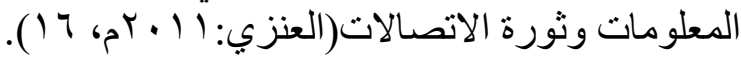

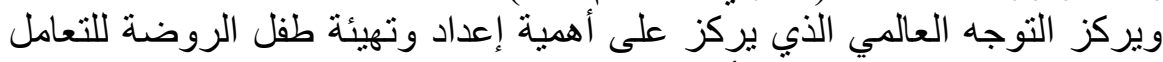

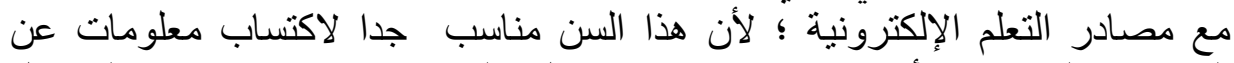

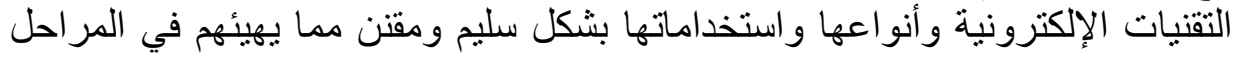

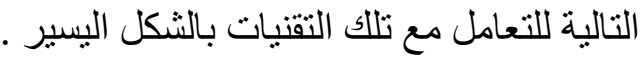

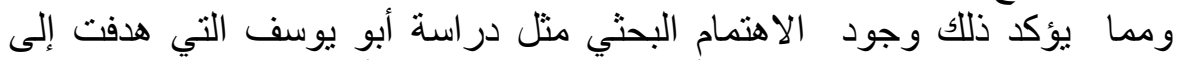

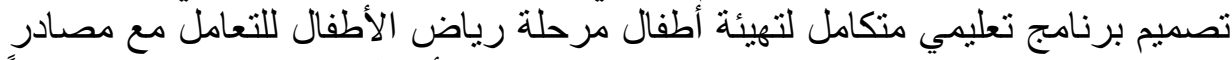

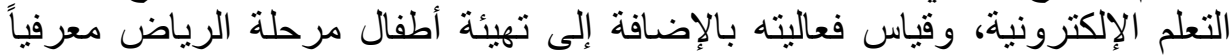

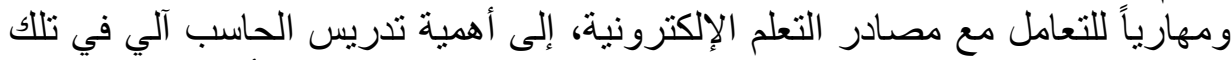

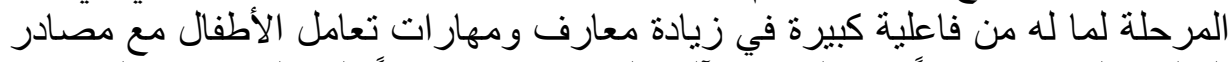

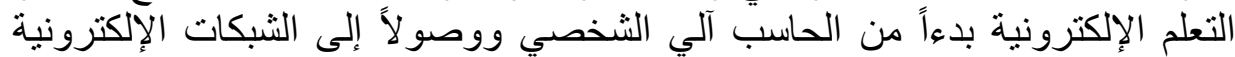
لإعداد جيل قادر على مو اجهة المتغير الت السربعة الميعة والمتلاحقة. 
و وذا على اعتبار أن تعلم الطفل مصادر التعلم الإلكترونية يوازي تعلمه للقراءة ألماء

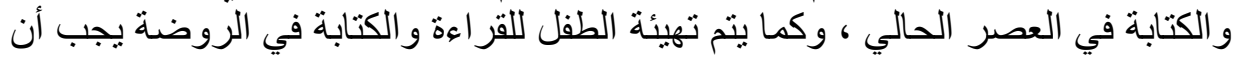

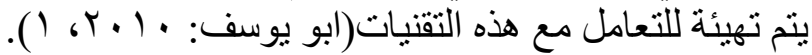

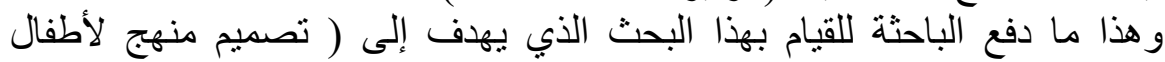

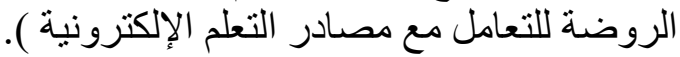
مشكلة الدر اسة: تظهر مشكلة البحث بوضوح من خلال ملاحظة أن مناهج المؤسسات التعليمية

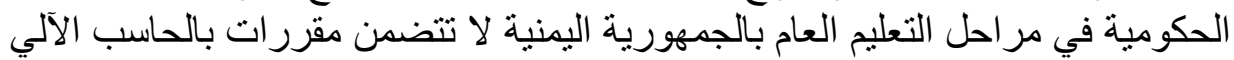

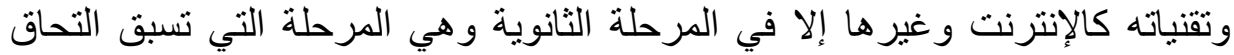

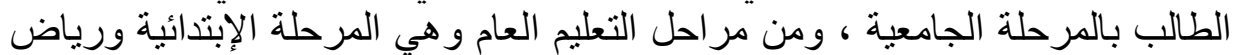

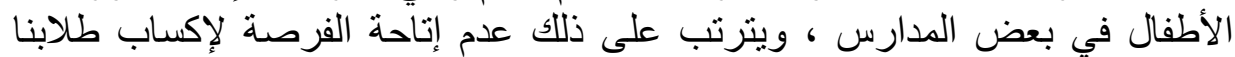

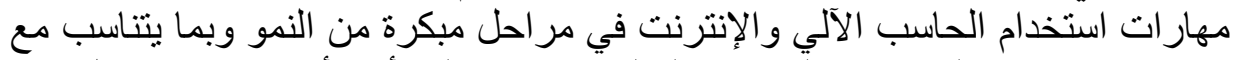

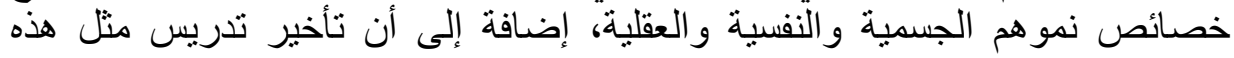

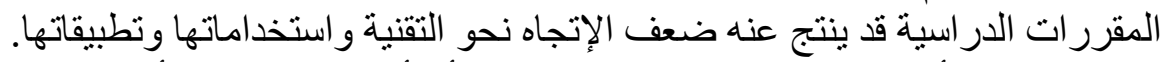

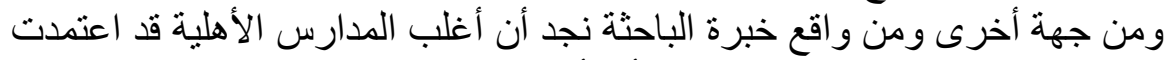

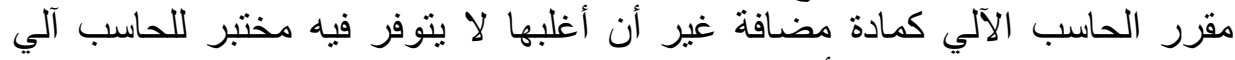

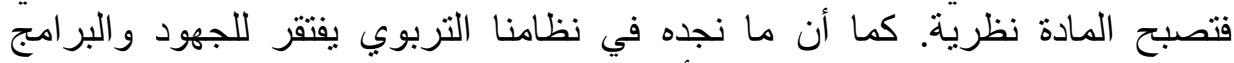

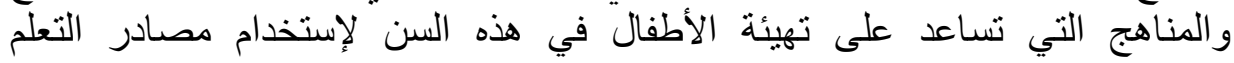
الإلكترونية.

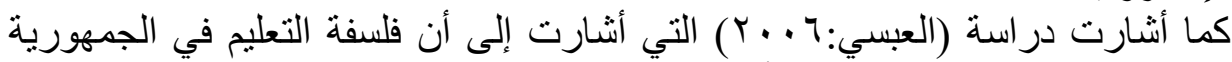

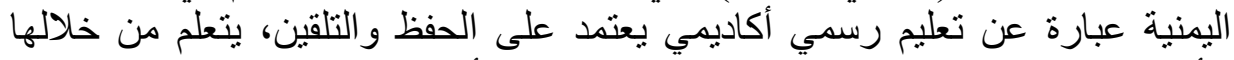

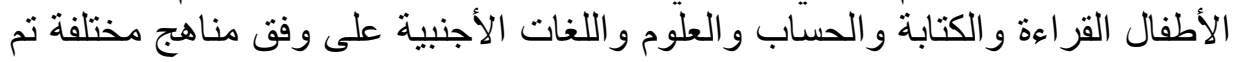

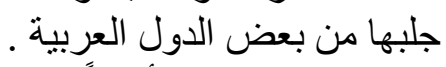

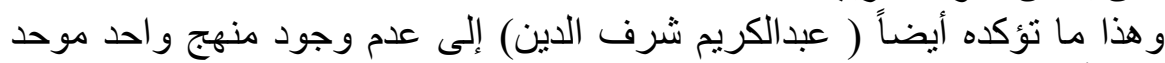

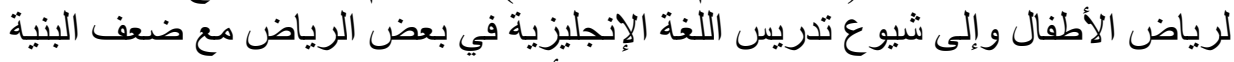

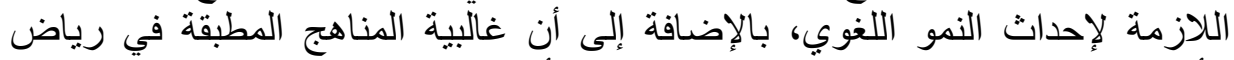

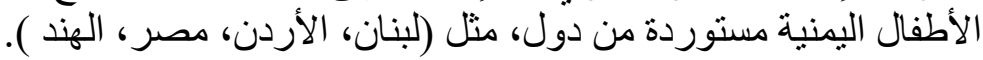

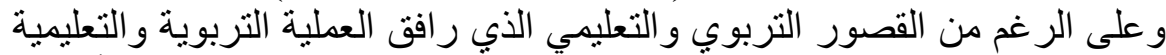

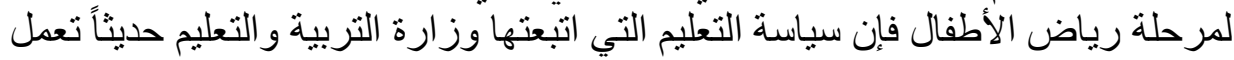

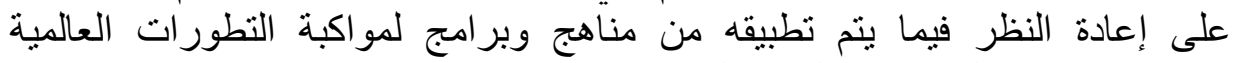

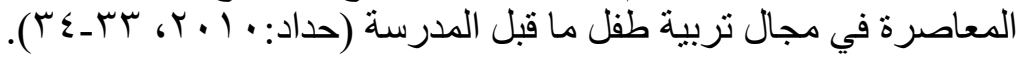


ومن هنا تظهر بوضوح مشكلة البحث الحالي والتي تتمثل في عدم الاهتمام بمصادر

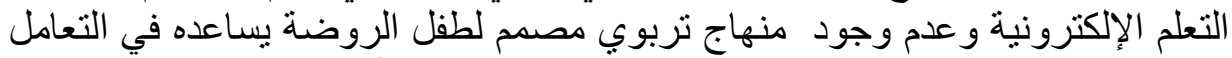

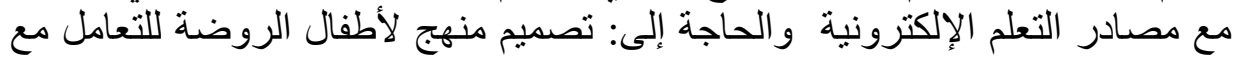
مصنادر التعلم الإلكترونية . مصلم الإكترو مصطلحات البحث :

من المعلوم أن كلمة " تصميم مشتقة من الفعل " صمم" أبي عزم ومضى على على أمره

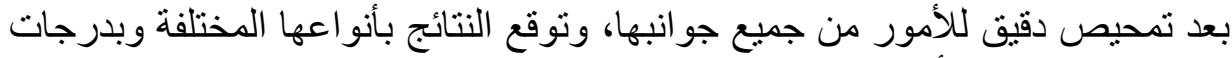

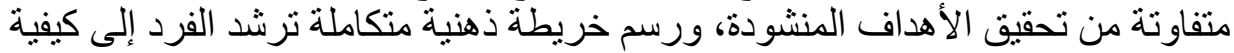
التنفيذ والسير قدماً، وبخطوات ثابنة فيها مرونة نحو التهو الهدف، وتوحي بتحمل المسؤولية

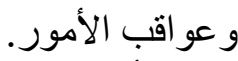
أما مفهوم التصميم فيعرفه الحيلة بأنه هندسة للثيء بطريقة ما على وفئ وفت محكات التهات

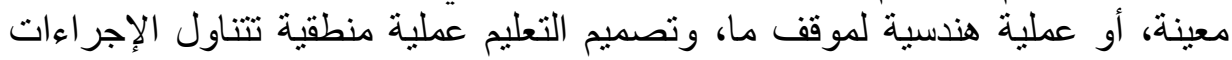

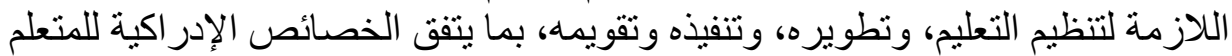

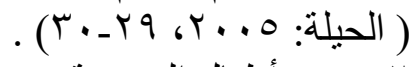

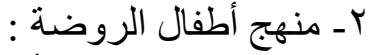

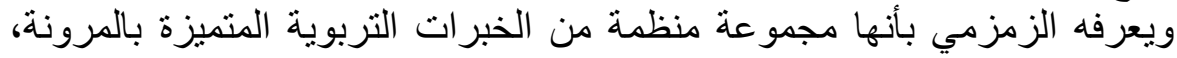

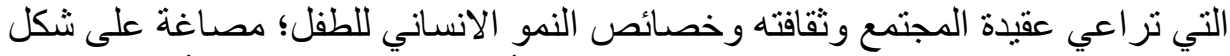

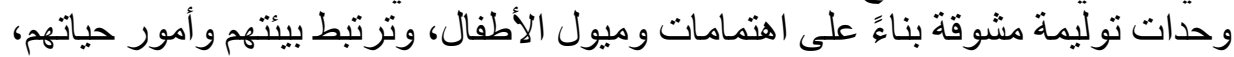

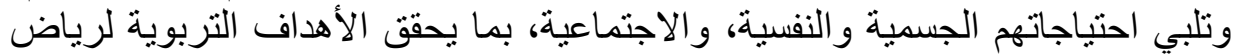

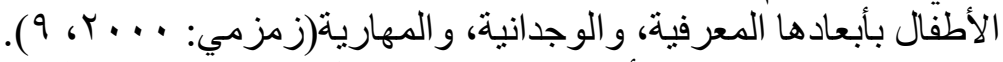

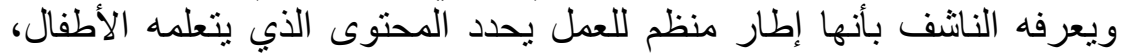

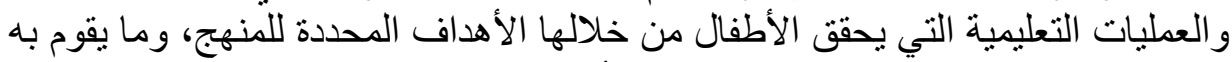

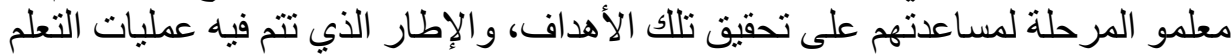

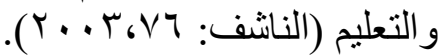

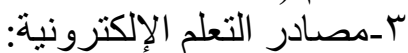

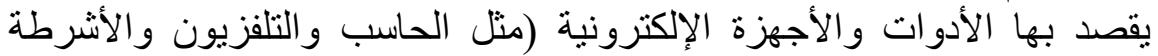

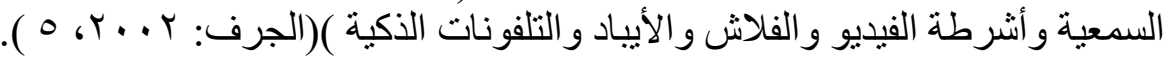
وتعرفها الباحثة : هي الأجززة أو الأدوات و البرامج الإلكترونية التي يمكن للطفل من خلال التعامل معها أكتساب المعلومات الادو المهار ات المخت الإلفة 
يعهف البحث الحالي إلى تصميم منهج لأطفال الروضة للتعامل مع مصادر التعلم

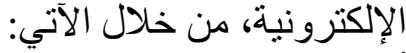

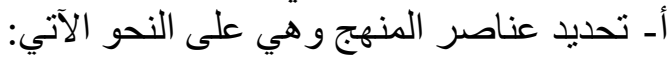

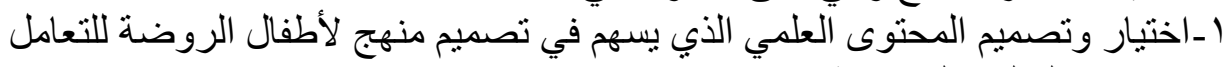
مع مصادر التعلم الإلكترونية. r-تحديد وصياغة الأهداف التي تسهم يسهم في تصميم منهج لأطفال الروضة للتعامل مع مصادر التعلم الإلكترونية. بـتحديد الطرق والأساليب التدريسية والأنشطة والوسية الوسائل التعليمية الملائمة في تصميم

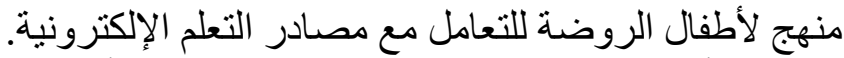
ع ـتحديد أساليب التقويم الملائمة في تصميم منهج لأطفال الروضة الرونة للتعامل مع مصادر التعلم الإلكترونية.

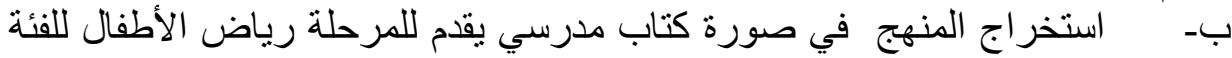

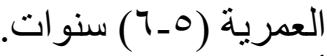
أهمية الدر اسة:

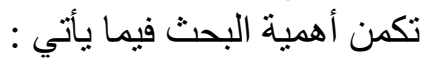

1 - إلقاء الضوء أهية على أهمية تهيئة طفل الرئية الروضة للتعامل مع مصادر التعلم الإلكترونية .

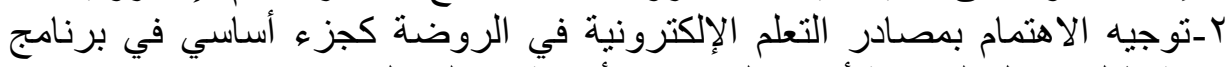

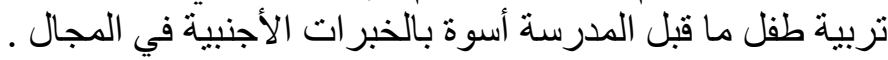

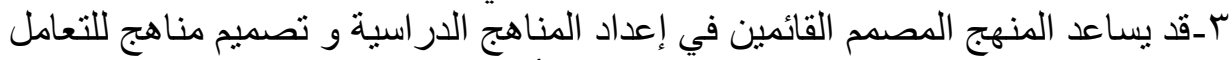

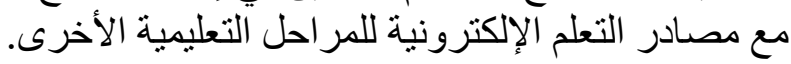

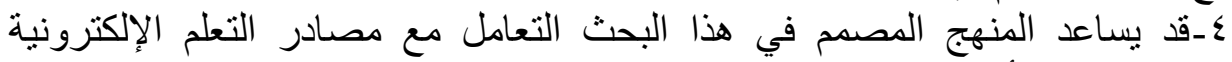
وتوظيفها في الأغر اض التهن التعليمية.

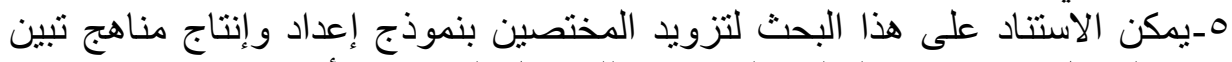

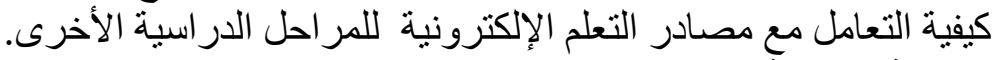
منهجية الدراسة:ّة اولاً: منهج الارسة الدراسة:

استخدم في هذا البحث المنه المنج الوصفي؛ لأنه الأنسب لتحقيق الأهداف من خلال

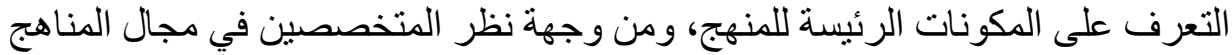

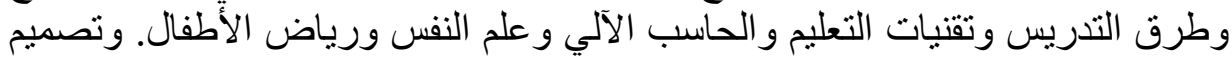
المنهج في ضوف ألتك المكونات الرئيسة. 


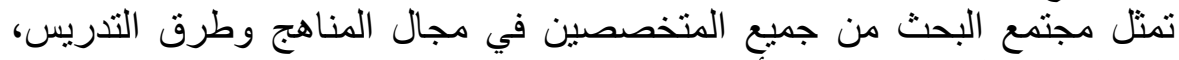

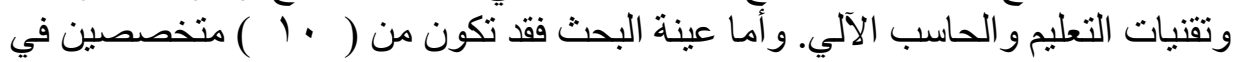
مجال المناهج وطرق التدريس، وتقنيات التعليم والحاسب الآلّي، و وعلم النفس ورياض الأطفال بجامعة الحديدة

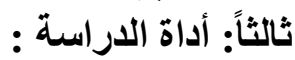

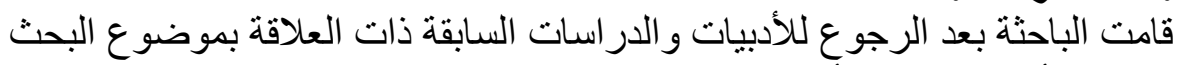

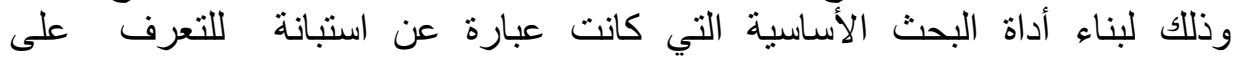

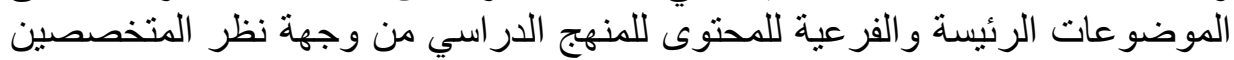
في مجال المناهج. وطرق التدريس ورياضج وراض الأطفال وتقنيات التعليم والحاسب الآلي، وقد اشنملت

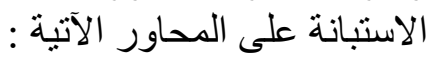
- المحور الأول : التعامل مع الأجهزة الألية : الحاسب الآلي و اللابتوب).

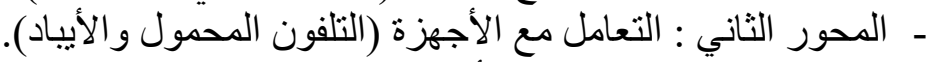

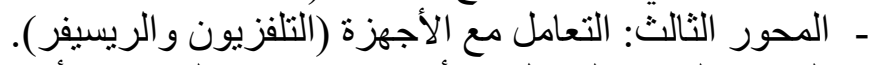

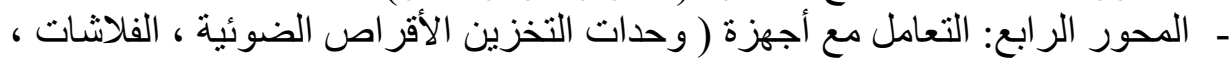
الذو اكر ، قارئ الذو الذو اكر). - المحور الخامس: التعامل مع جهاز (البلاي ستيشن محطة الألعاب).

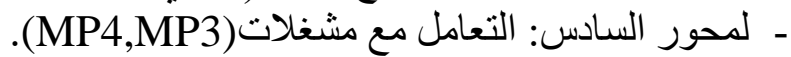

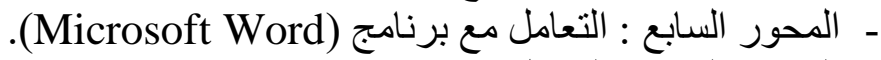

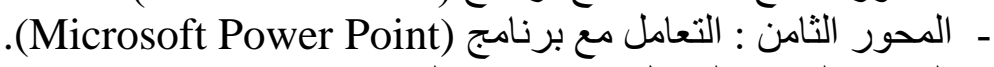

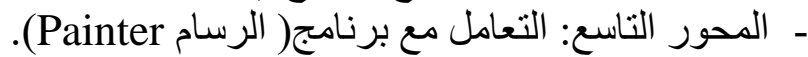

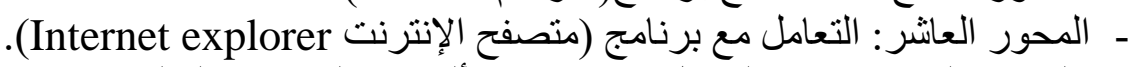
- ـ المحور الحادي عشر: التعامل مع برامج (الألعاب الإلكترونية التعليمية).

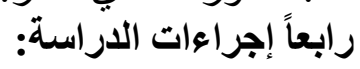
قامت الباحثة بالخطوات الترات الآتية : باتهاء

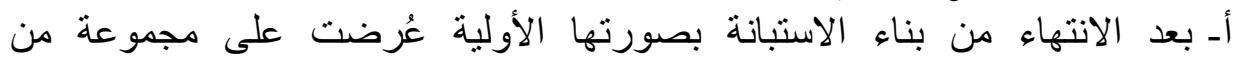

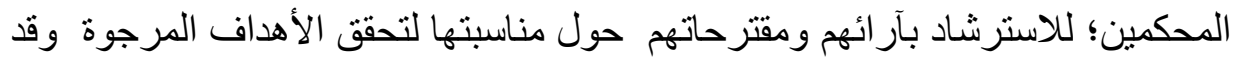

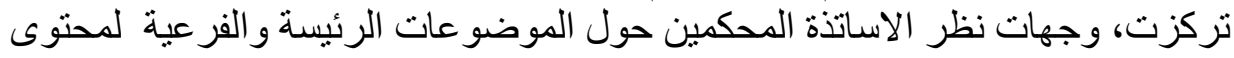

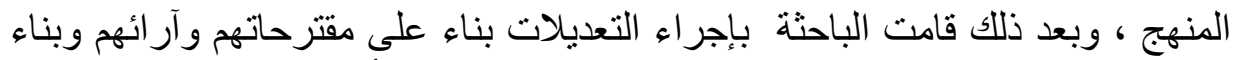

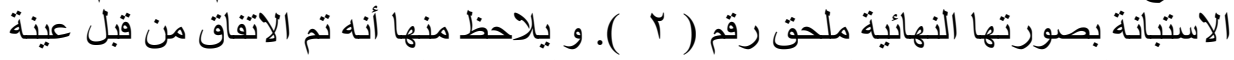

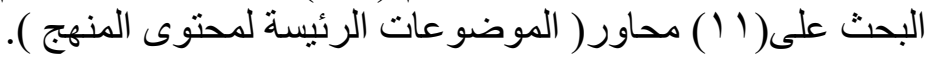


ب- بمن خلال الاطلاع على الآتي: 1 - مناهج بعض الدول الاطل مثل مناهج كاليفورنيا وكندا.

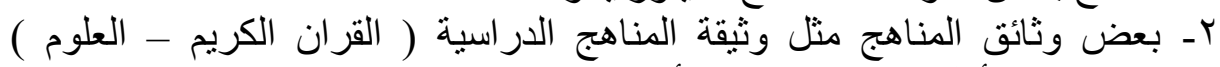
للصفوف الستة الأولى لمرحلة الته التعليم الأساسي.

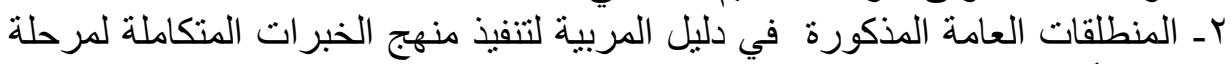

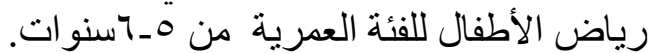

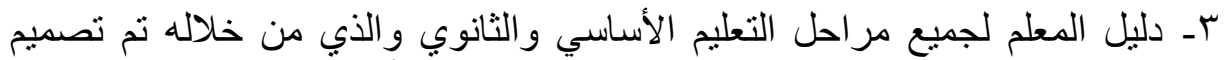

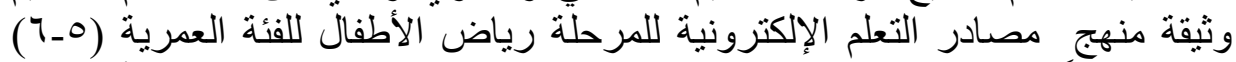

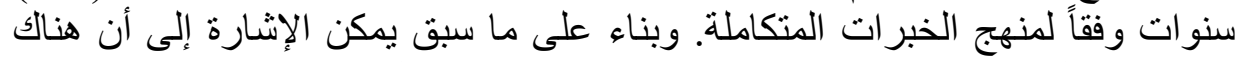

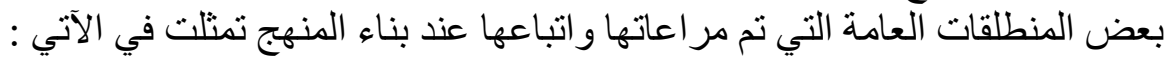
المنطلقات العامة أو لاً : أسس فلسفة الترانة التربية في اليمن.

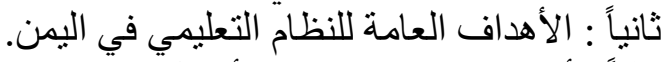
ثالثاً: : أهداف مرحلة رياض الأدة الأطفال.

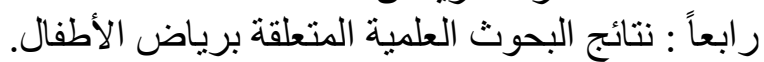

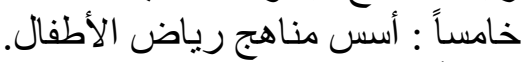

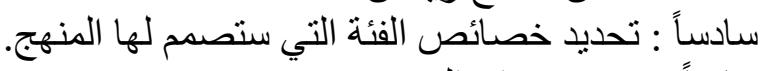
سابعاً : تحديد عنوان : تصديد المنهج.

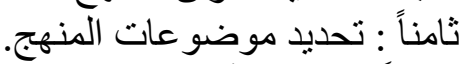

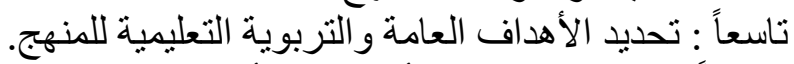

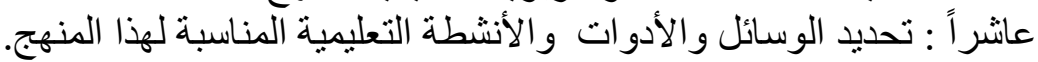
الحادي عشر: تحديد الطرائق والاستراتيجيات المناسبة للاستخدام لتدريس أطفال

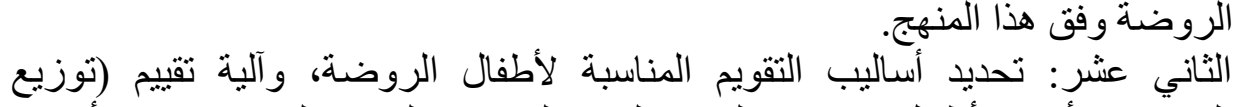
الدرجات) أداء الأطفال، وتقسيم الوقت اللازم لتدريس المنهج الدراسي في الأسبوع الو الود. لثالث عشر : جدول توزيع موضو عات المنهج على شهور السنة الدر اسية.

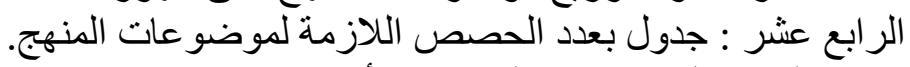
يتكون الكتاب المنهجي من الوحدات الودات الأتية:

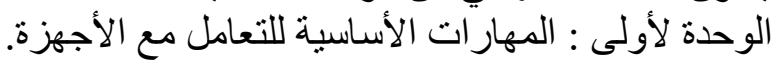
ا ـ الحاسب آلي و اللابنوب.

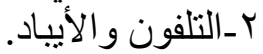




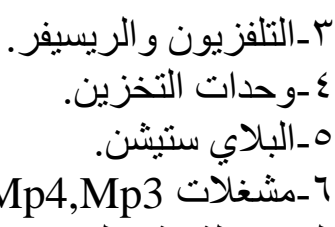
الوحدة الثانية : المهار ات الأساسية للتعامل مع البر امج التطبيقية: ا_ ـالتعامل مع برنامج (Microsoft Word)

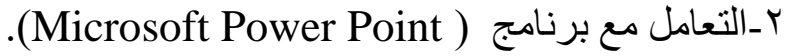

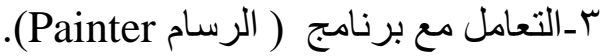

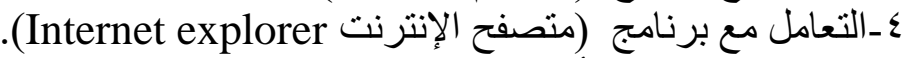
هـ التعامل مع بر امج الألعاب الإلكترونية التعليمية.

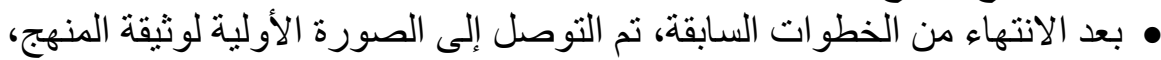

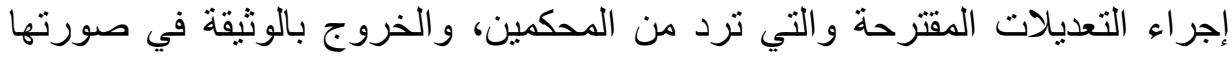

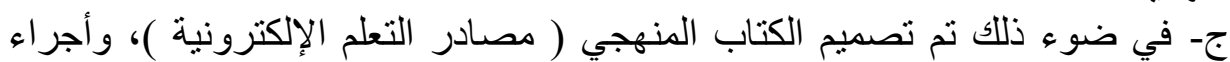
التعديلات المقترحة التي أوصى بها المحكمون، ومن ثم إخر اج الكتاب بصورتهابه النهائية.

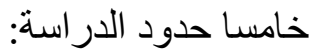
ا ـحدود العلمية: اقتصر البحث على تصميم منهج لأطفال الروضة للتعامل مع مصادر التعلم الإلكترونية. r-حدود البشرية: اقتصر البحث على مرحلة رياض الأطفال للفئة العمرية (7-7)

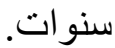
المبحث الأول- الإطار النظري والاراسات السابقة

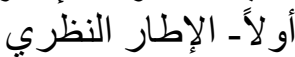

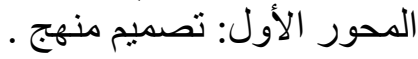

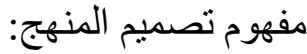

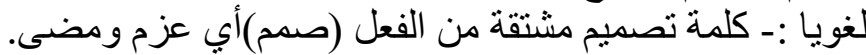

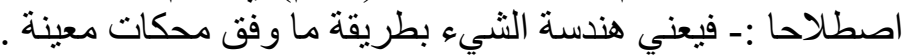

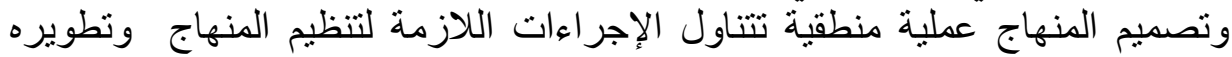

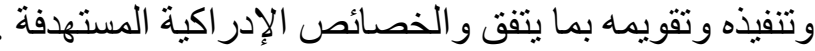

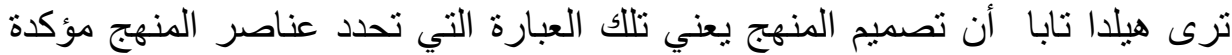

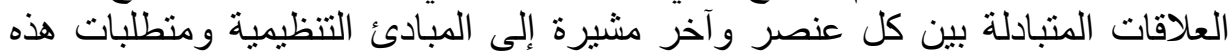
المبادئ للظروف الإدارية التي تعمل في ظل إنل إطار معين.

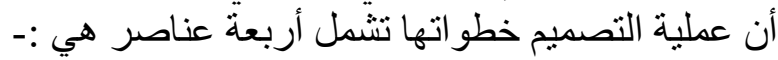




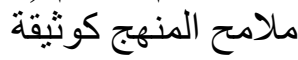

وثثية المنهج / تمنل الإطار العام الذي يحكم ويوجه عمليات المنهج المختلفة المتعلقة ببناء وتطوير المنهج.

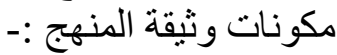

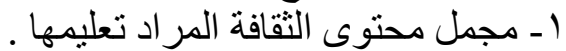

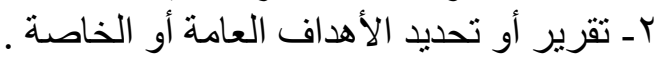

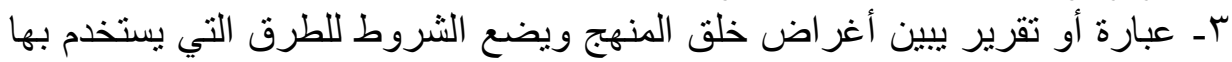
وهي قو اعد عملية التنفيذ

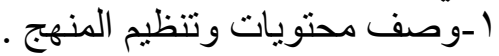

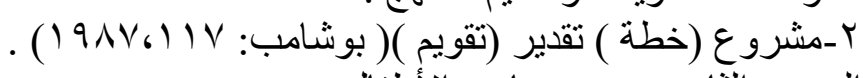
المحور الثاني :بمنهج رياض (خفير الاطفال :

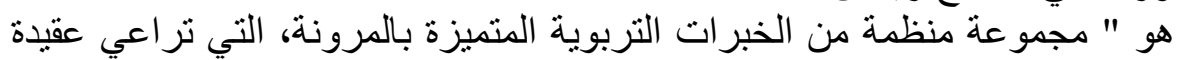

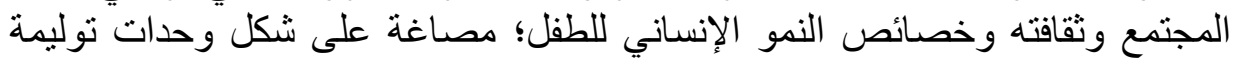

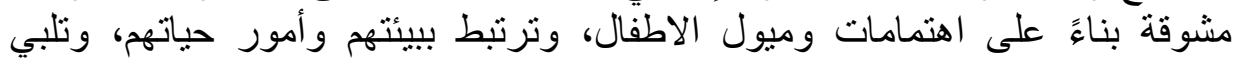

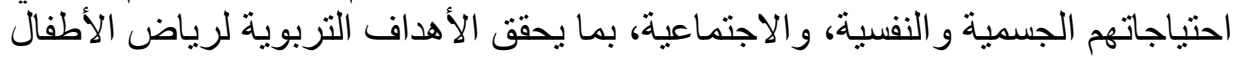

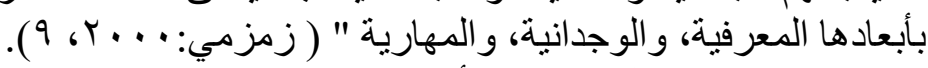

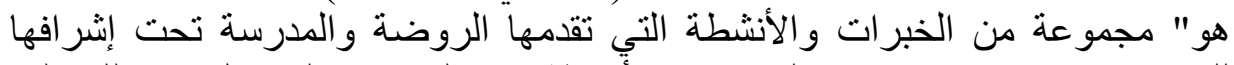

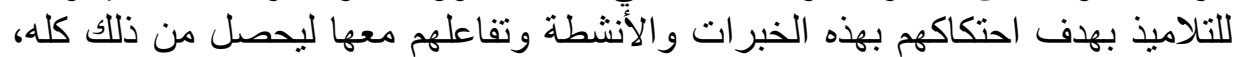

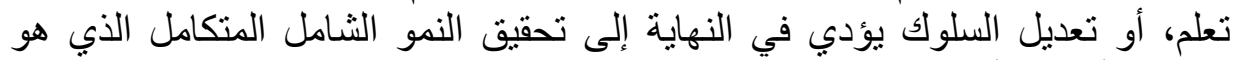

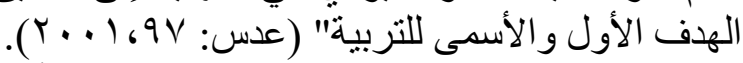

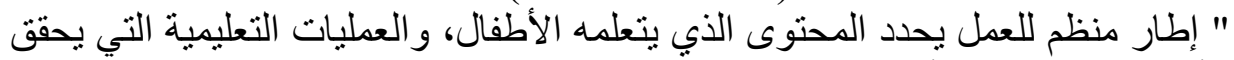

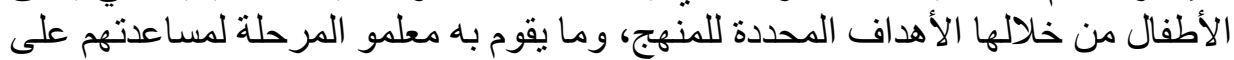

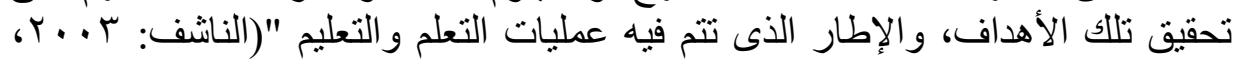

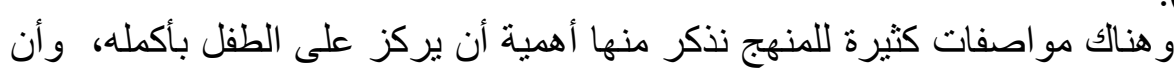

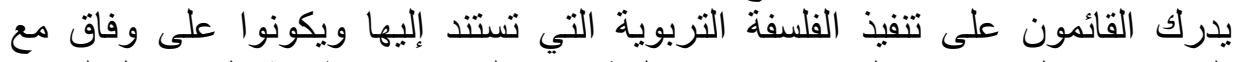

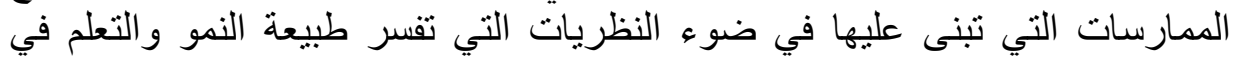

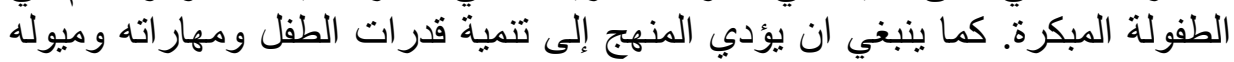


واهتماماته في شتى المجالات، وأن يعتبر اللعب طريقة الطفل في التعلم (الناشف:

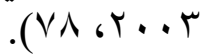
يعرفه ( البرتي )أنه كل النشاطات التي تقدمها الروضة لأطفالها بهدف تحقيق تغيير ات في سلوكهم في ضو ضو النه فلسفتها و أهدافها.

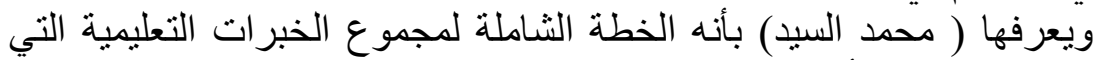

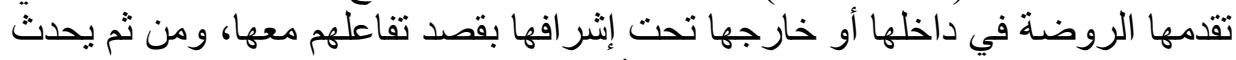
التعلم، مما يؤدي إلّى تحقيق النمو الثنامل للأطفال.

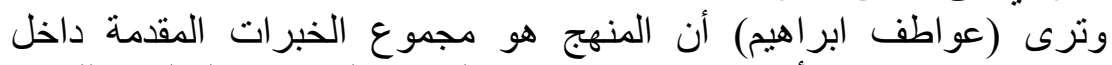

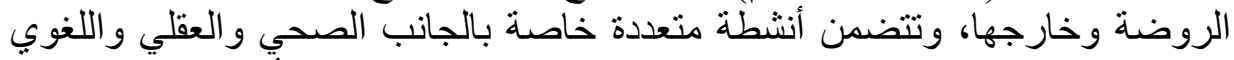

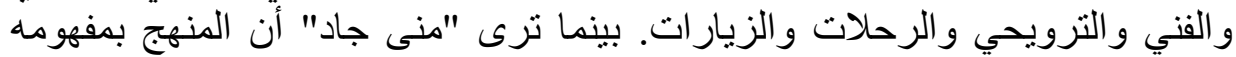

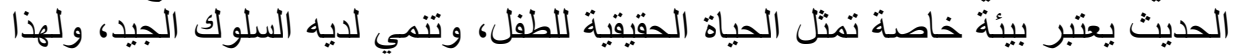

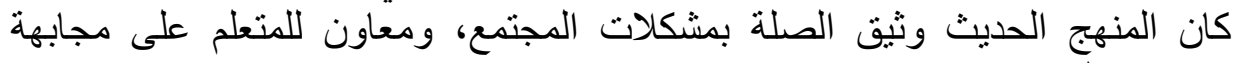

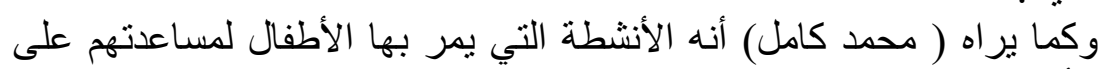
مشكلات الحياة.

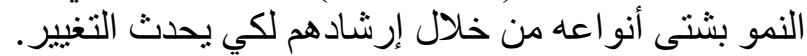

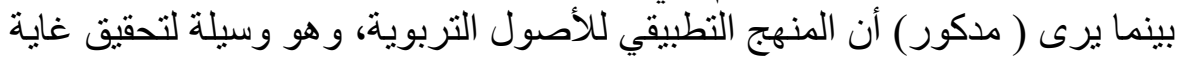

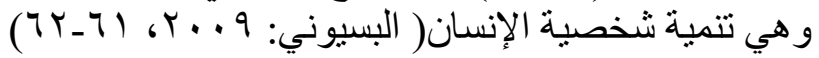
المحور الثالث: مصادر التعلم الإلكترونية.

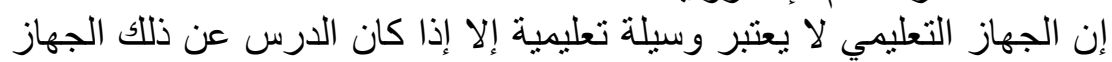

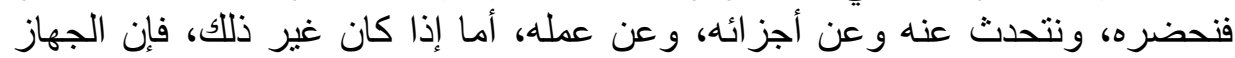

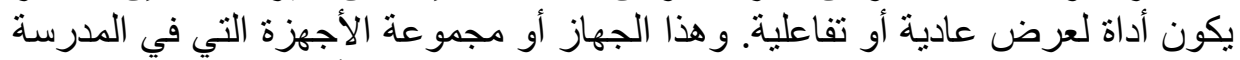

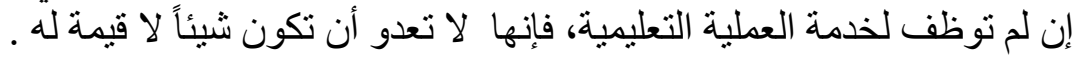

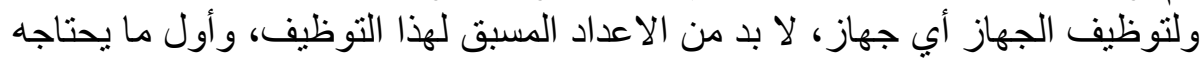

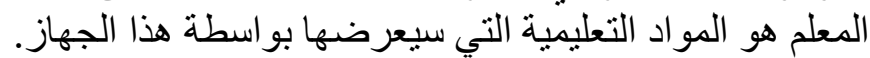

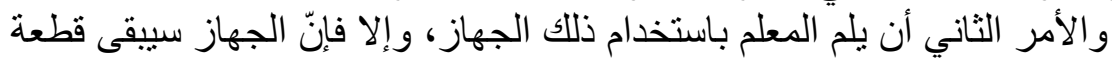

زينة تزين مستودع المدرسة أو غرفة الأنة الإدارة.

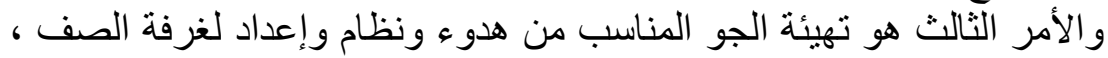

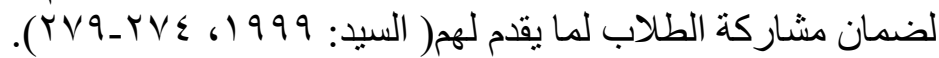

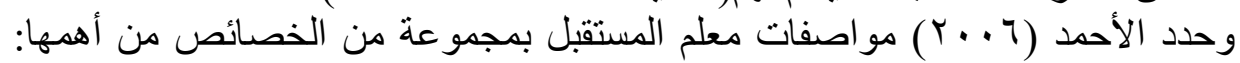

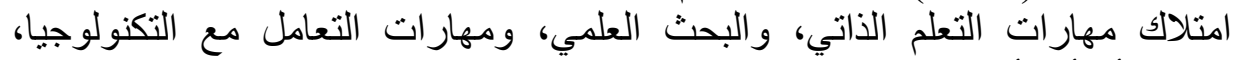

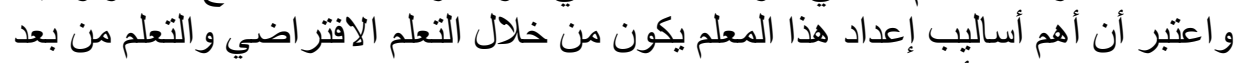

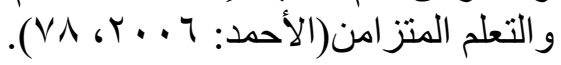


إيجابيات وفو ائد مصادر التعلم الإلكترونية للطلاب ( الأطفال):

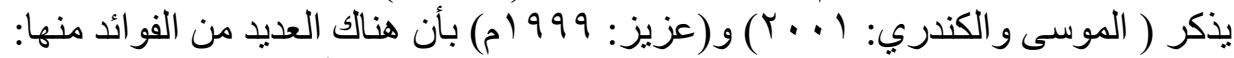

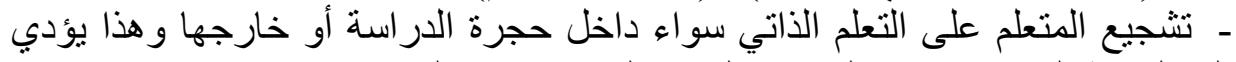

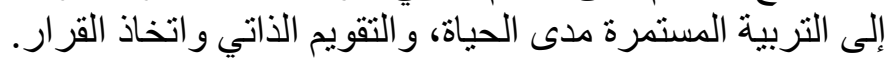

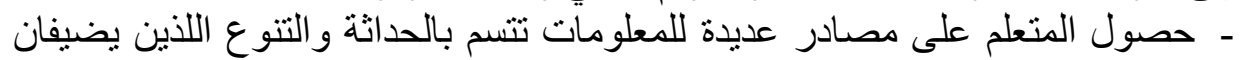

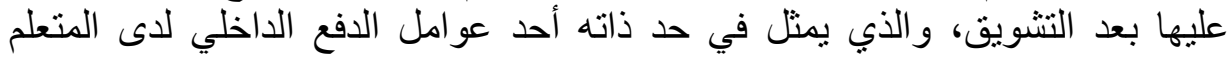

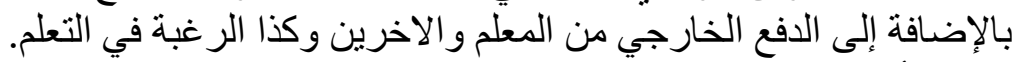

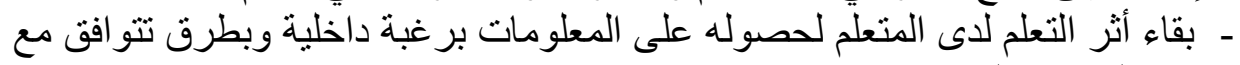
قدر اته الذهنية و النفسية. - تطوير مهار ات الطلاب على استخدام الحاسب آلي.

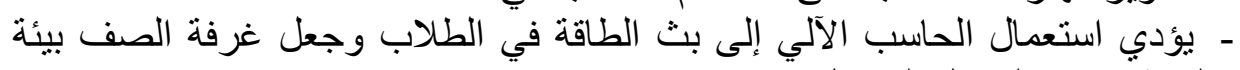
تعليمية تمتاز بالتفاعل المتبادل.

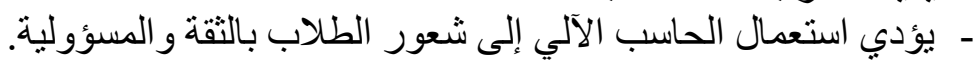

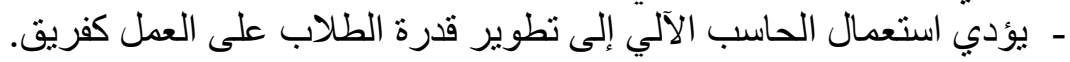

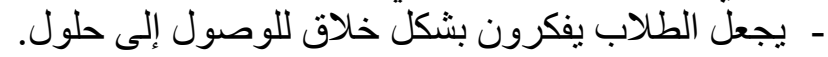
- ميادة مستوى التعاون بين المعلم و والطلاب. - ـ وجود المرونة في التعلم، فالطالب يتعلم منتى وكيفما شـاء.

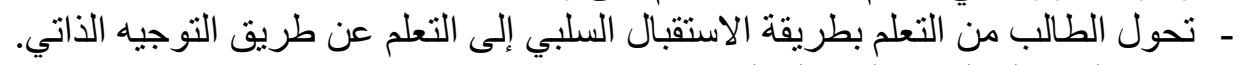

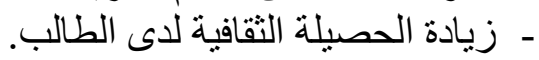

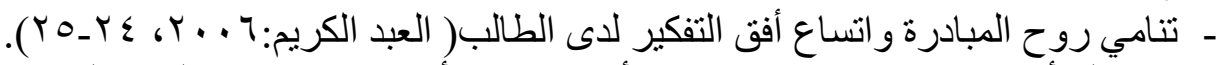

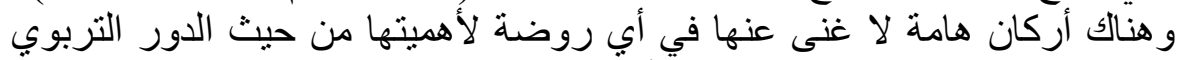

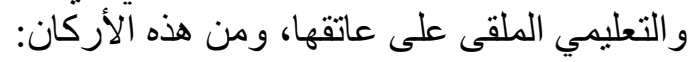

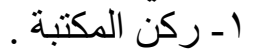

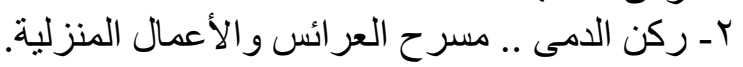

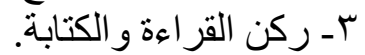

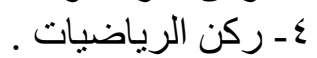
0- ك- ركن الفن و الأشغال اليدوية. 7- - ت ركن اللعب الابتكاري.

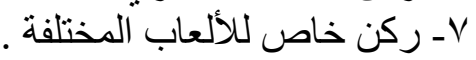

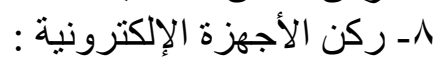

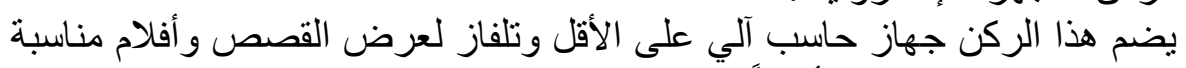

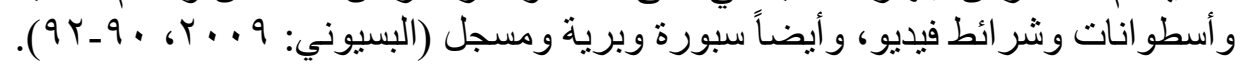




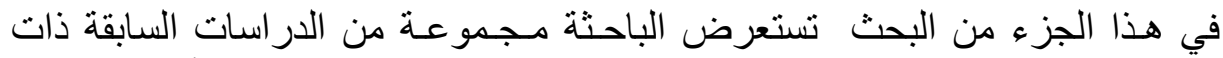

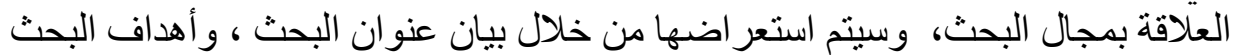

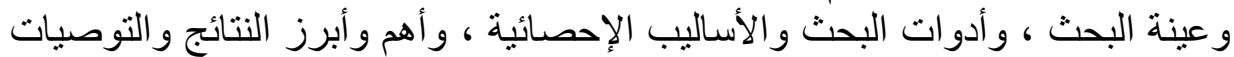

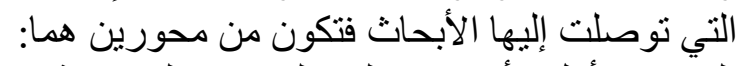

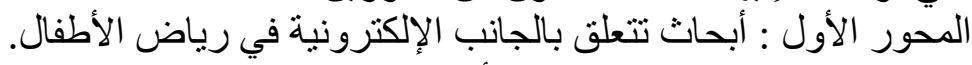
المحور الثاني: تعليق عام على الأبحاث البات السابقة. المحور الأول: دراسات تعلقعلق بمصادر الأبحاث التعلم الإلكترونية في رياض الأطفال وهي

$$
\text { ألى النحو الآتي: }
$$

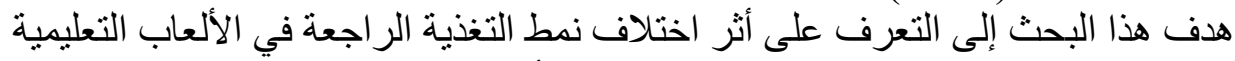

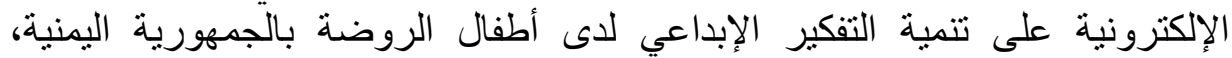

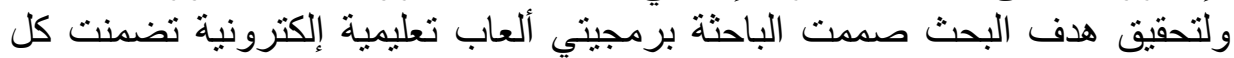

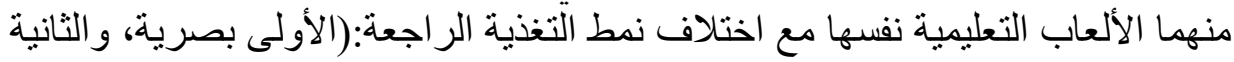

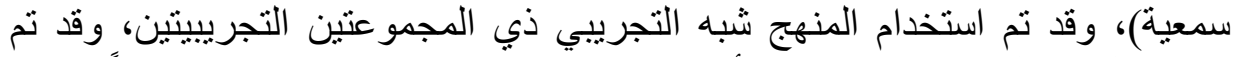

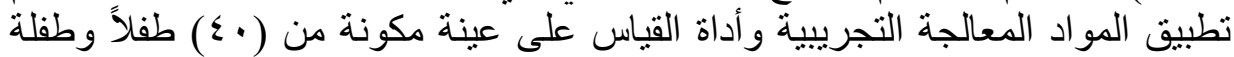

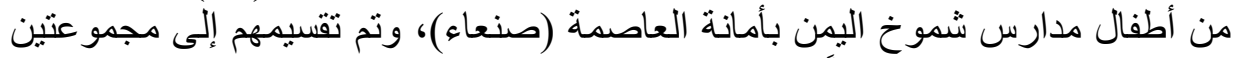

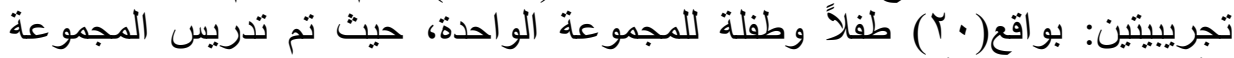

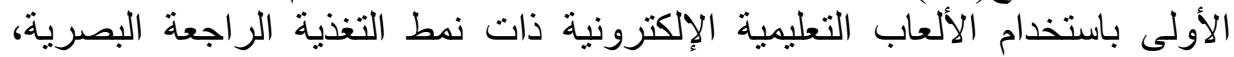

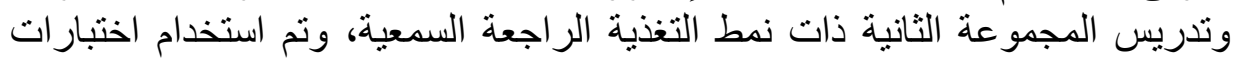

$$
\text { تور انس للتفكير الإبداعي. }
$$

$$
\text { وقد أسفرت النتائج على الإبداعد النحو الآتي : }
$$

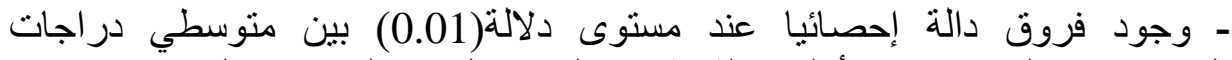

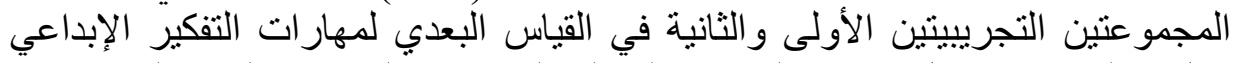

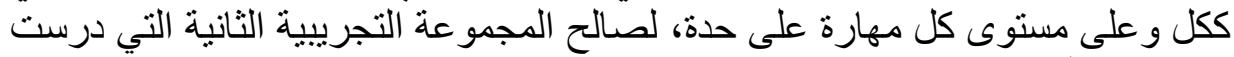

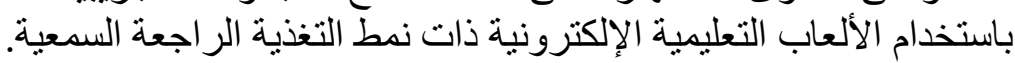

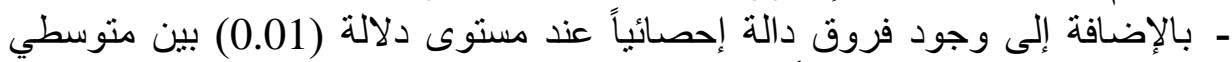

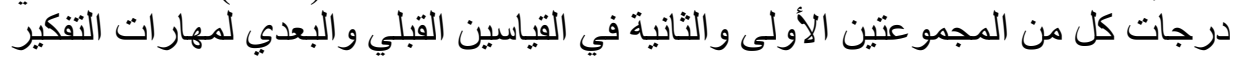

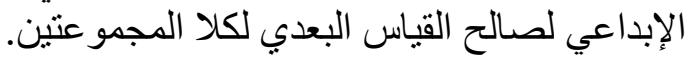

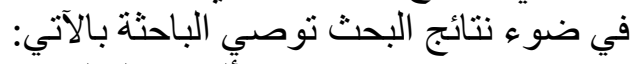

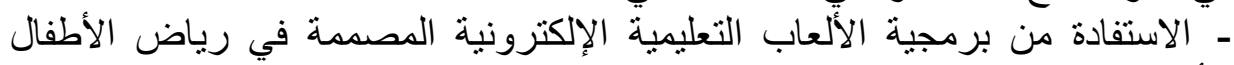
الأخرى بالجمهورية اليمنية. 
- تشجيع معلمات رياض الأطفال على استخدام البرمجيات التعليمية عامة.

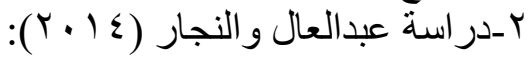
هدف هذا البحث إلى معرفة فاعلية برنامج ألعاب تعليمية إلكترونية في تتمية

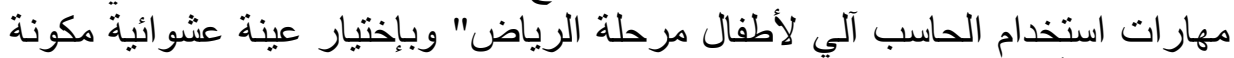

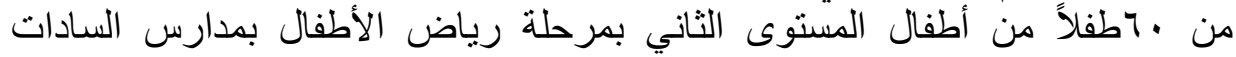

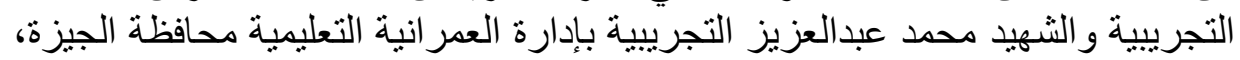

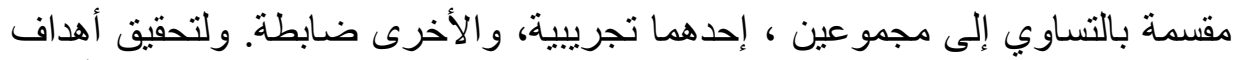

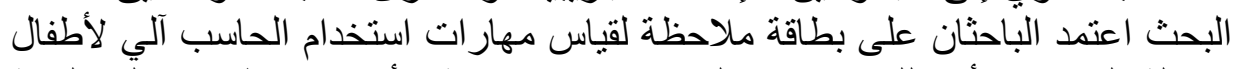

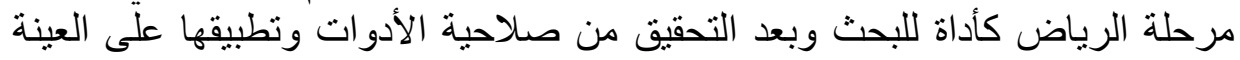
وتحليل البيانات توصل الباحثان إلى النتائج التالية :

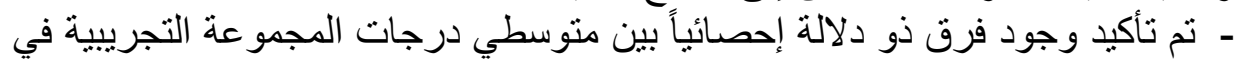

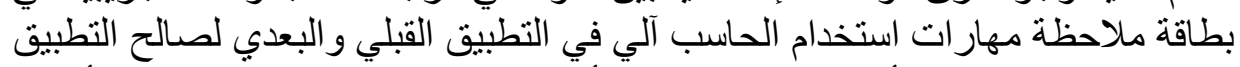

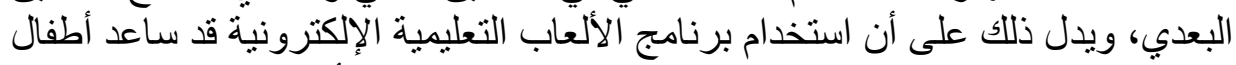

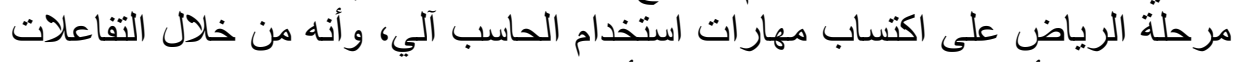

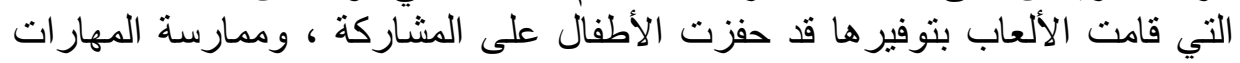
وفن ثم تنمية مهار اتهم.

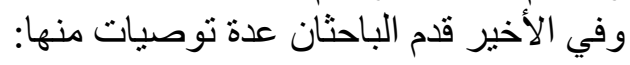

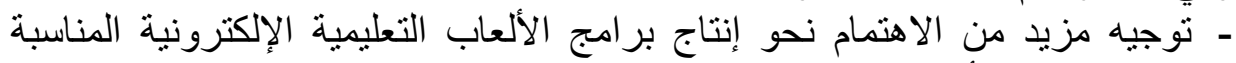

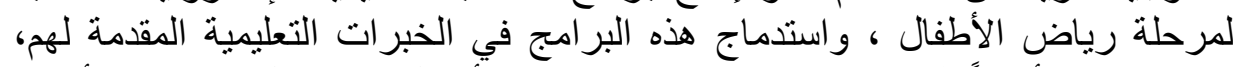

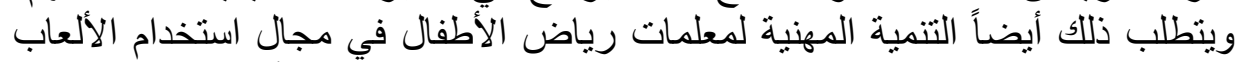

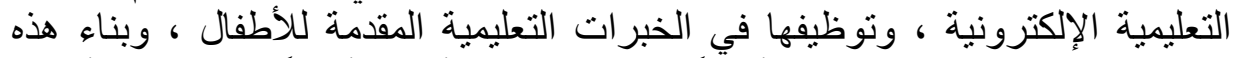

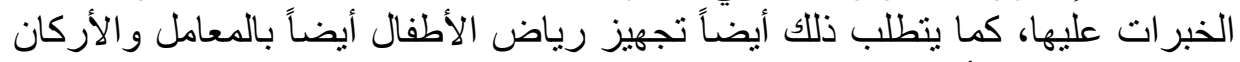

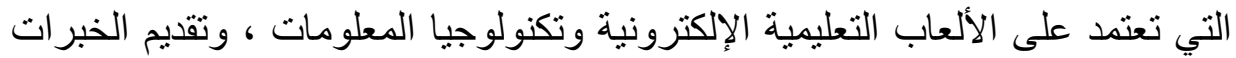

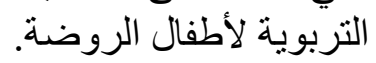

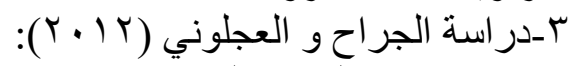

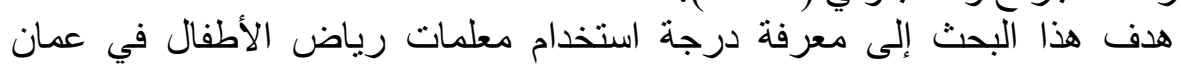

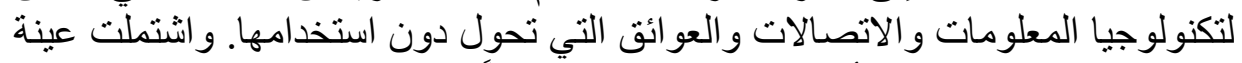

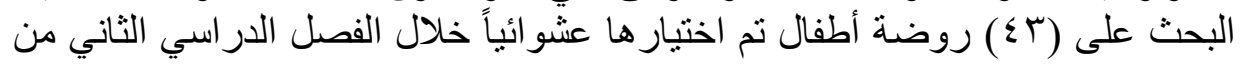

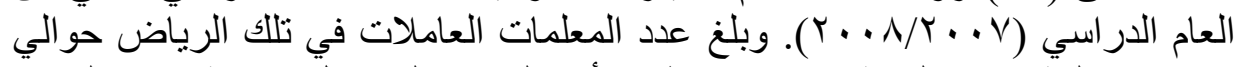

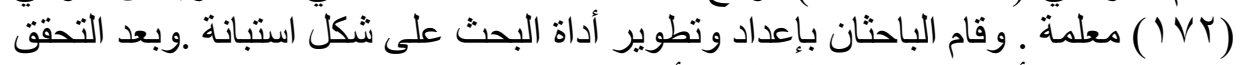

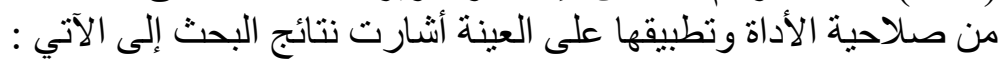


ا-وجود عوائق كثيرة تحول دون استخدام معلمات رياض الأطفال لتكنولوجيا

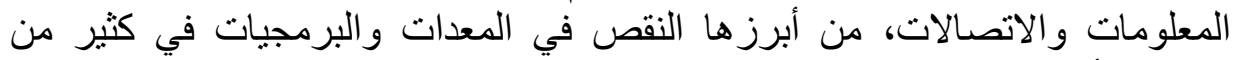

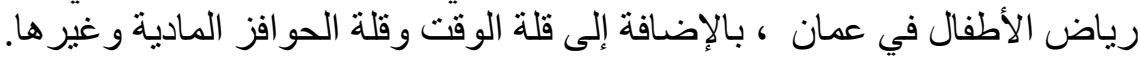
Y-وجود ضعف لَّى معلمات رياض الأن الأطفال بشكل عام في مجال استخدام تكنولوجيا

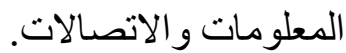
في ضوء نتائج هدا البحث، ومن أجل المبات المساعدة في تطوير الواقع الحالي لاستخدام

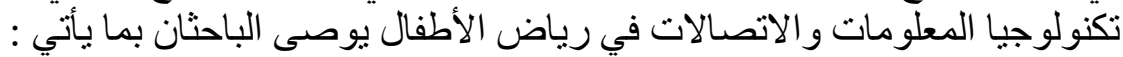

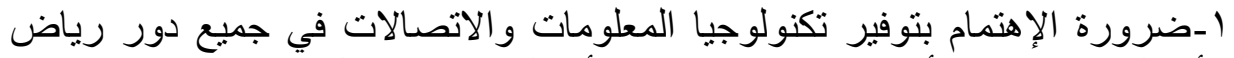

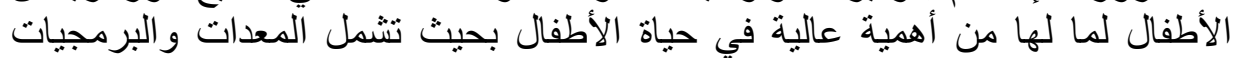
المناسبة. r-إعادة تأهيل وتدريب معلمات رياض الأطفال في مجال استخدام تكنولوجيا

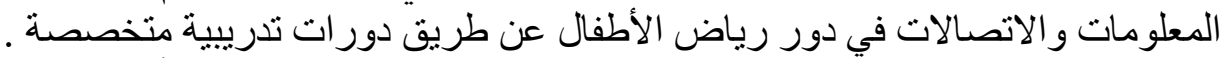

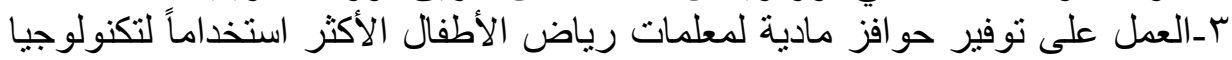

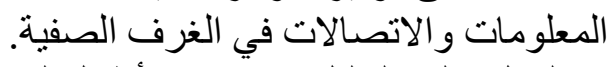

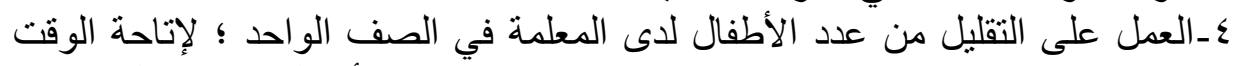

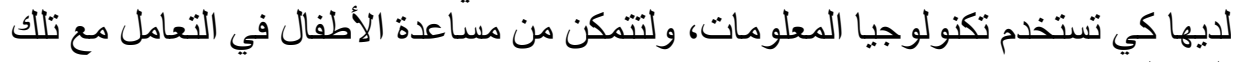
التكنولوجيا.

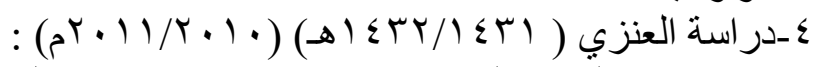

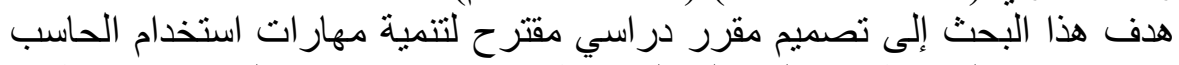

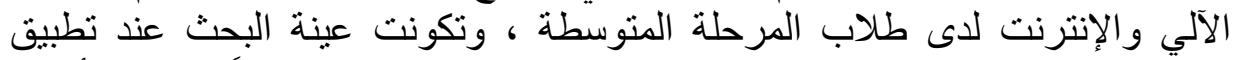

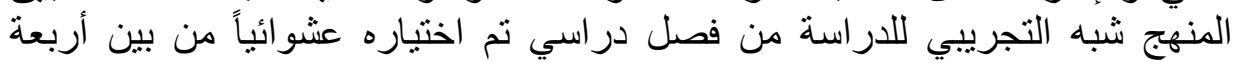

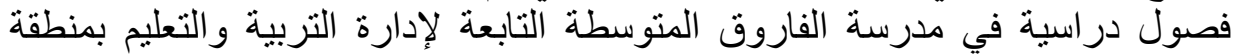

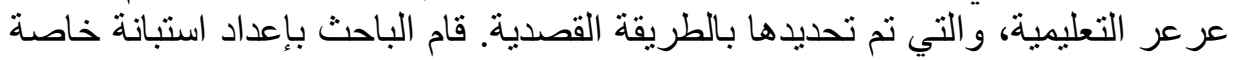
للتعرف على وجهة نظر المتخصصين في المكونات الرئيسة للمقرر الدراسي المهي المقترح

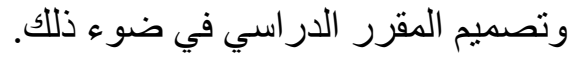

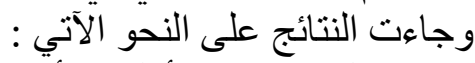

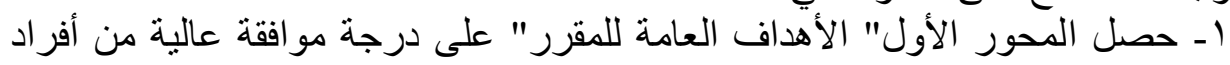

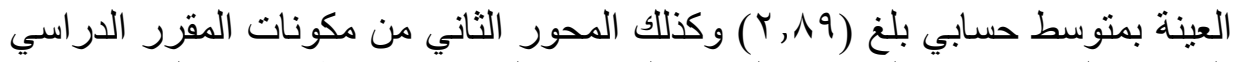

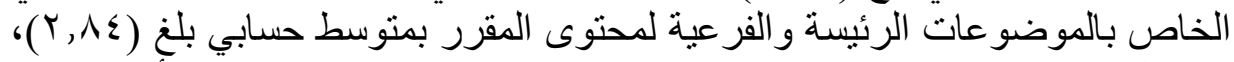

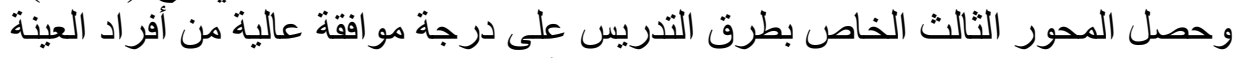

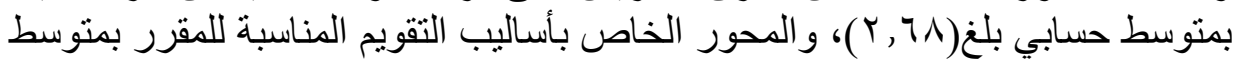

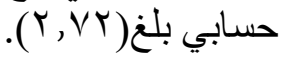


r- حصل المحور الخامس ( الوقت اللازم لتدريس المقرر ) على درجة مو افقة متوسطة

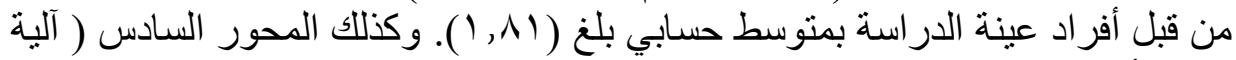

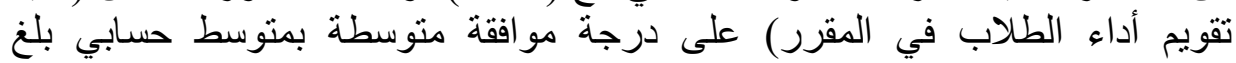

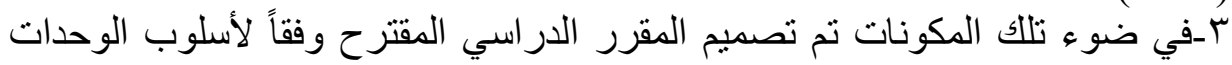

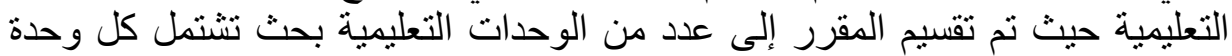

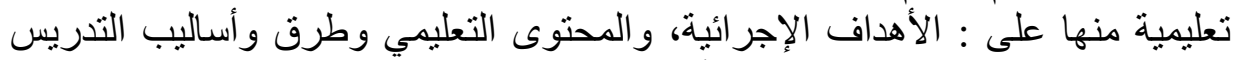

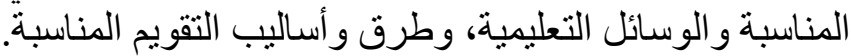

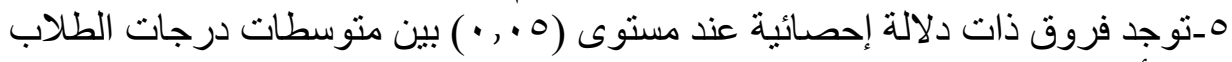

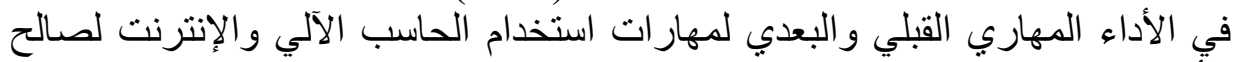

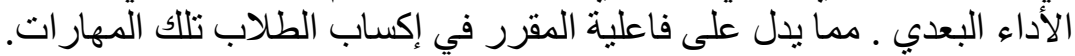

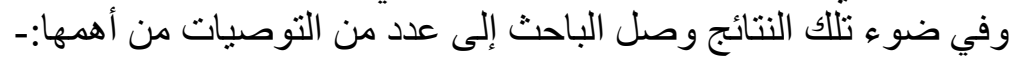

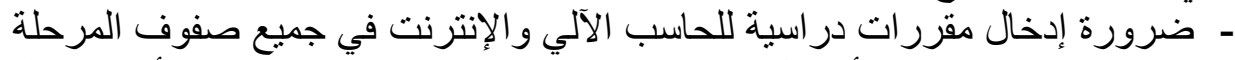

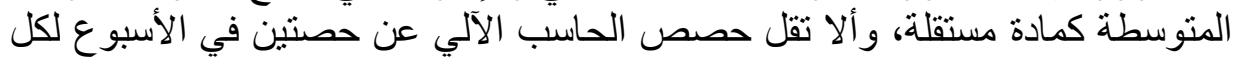

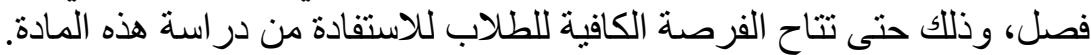

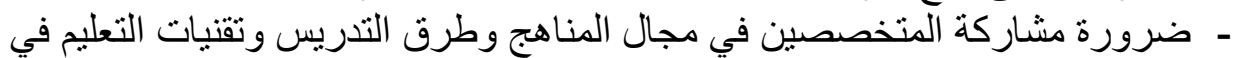

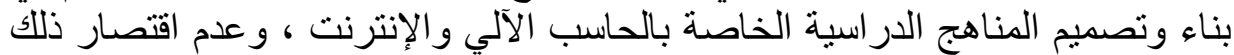
على المتخصصين في مجال الحاسب الآلي وتقنية المعلومات.

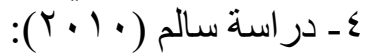

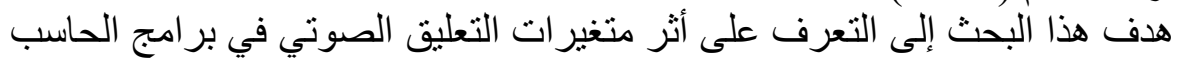

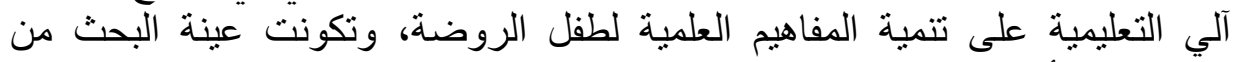

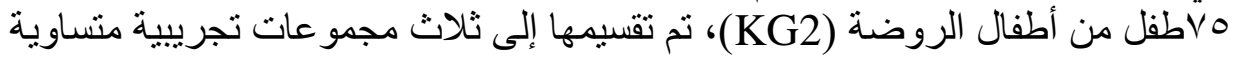

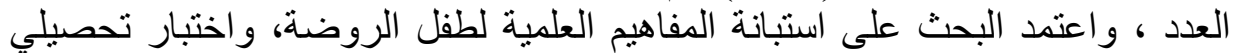

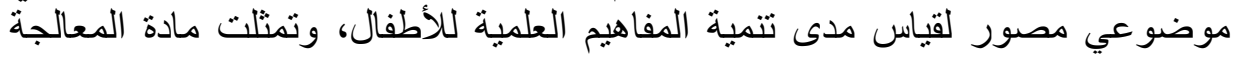

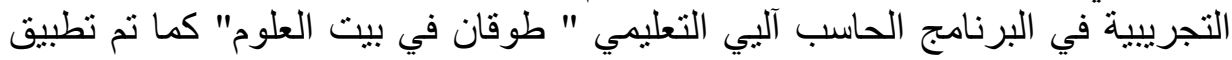

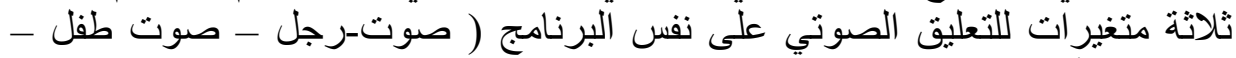

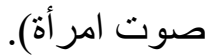

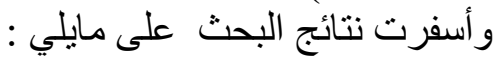

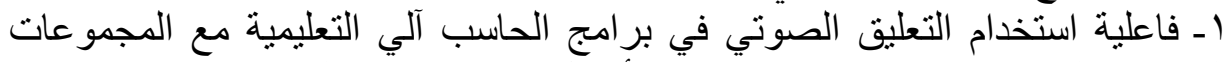

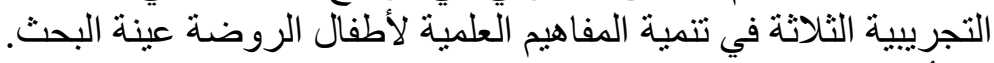

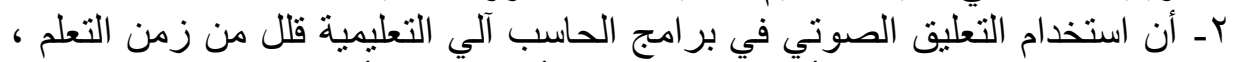

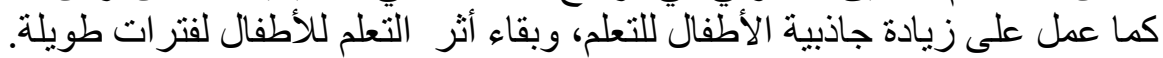




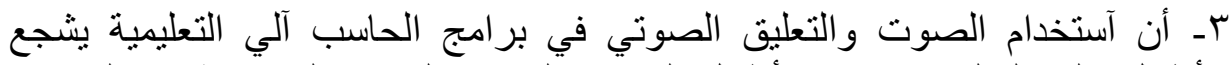
الأطفال على التعلم، ويكسب الأطفال المفاهيم ألمراد تعلمها، والمبن المتضمنة في البرنامج

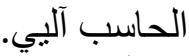
عـ أن الجمع بين الصوت والصورة في وقي وقت واحد ساعد على تعلم و اكتساب الأطفال

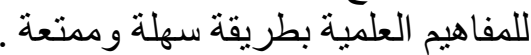
7ـأن مخاطبة القائم بالتعليق الصوتي للطفل في البرنامج يثير اهتمامه ويزيد من تركيزه V- تفوق أطفال المجموعة التجريبية الثانية صوت صوت الطفل يليها المجموعة التجريبية

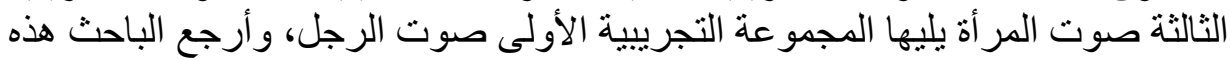

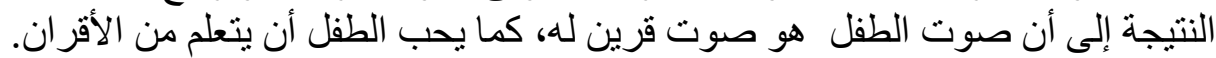

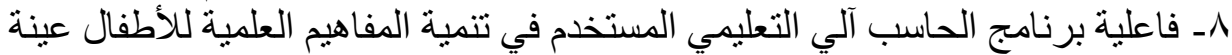

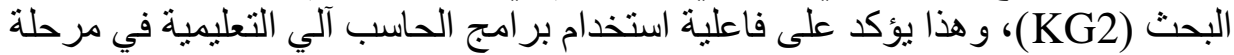
رياض الأطفال. ولدى الباحث العديد من التوصيات أهمها :

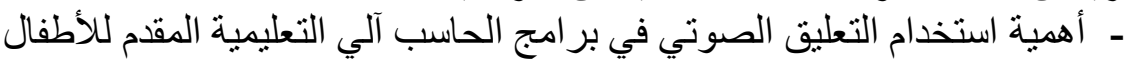

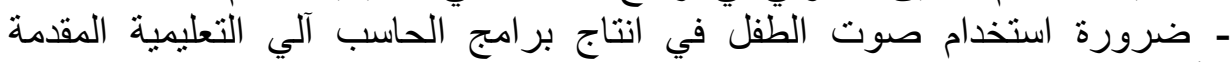

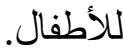
- ضرورة استخدام بر امج الحاسب آلي التعليمية في تتمية مفاهيم ومهارات أطفال

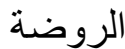

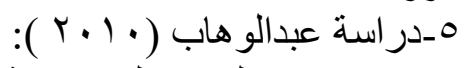

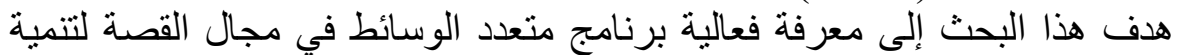

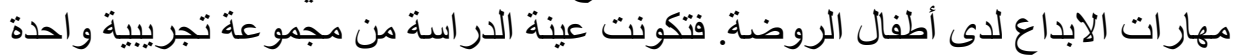

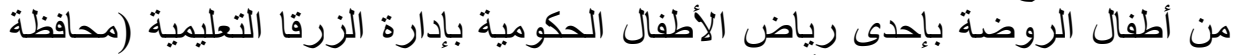

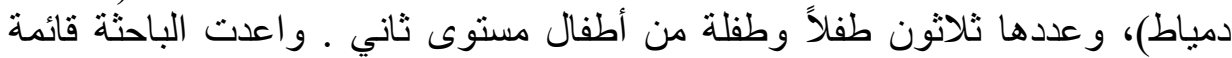

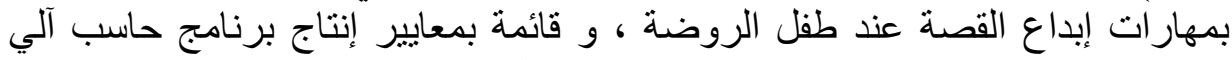

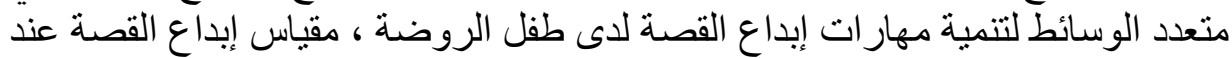

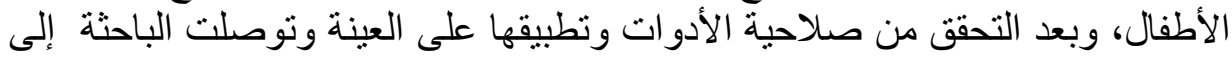

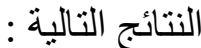

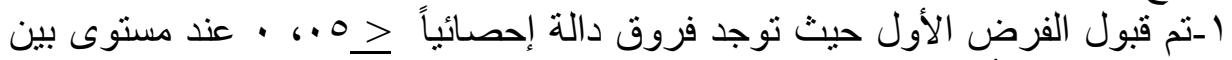
منوسط درجات أطفال المجموعة التجريبية في التطبيق القبلي و التطبيق البعائ البعدي لمقياس الإبداع لصالح التطبيق البعدي.

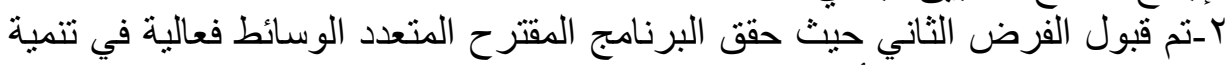

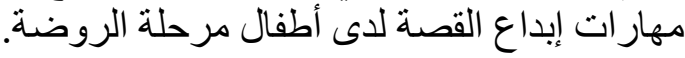




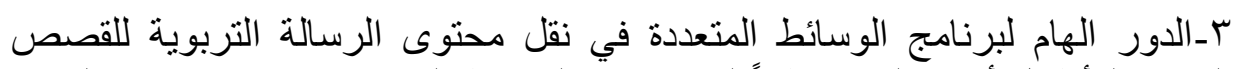

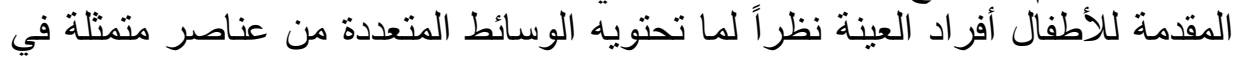

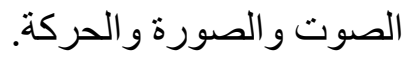
ع ـقدرة البرنامج المتعدد الوسائط في زيادة إدر الك الطفل ؛ لأنها نربط ما يثـاهده الطفل

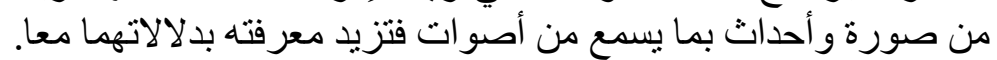

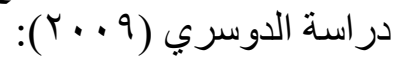
هدف هذا البحث إلى التعرف على على مدى استخدام الانترنت في مدارس رياض

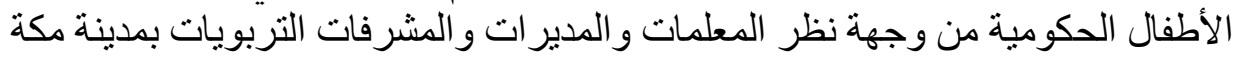

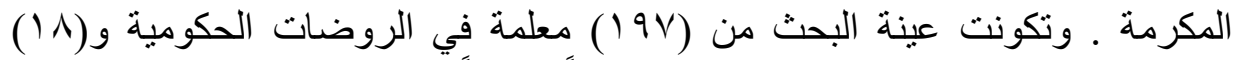

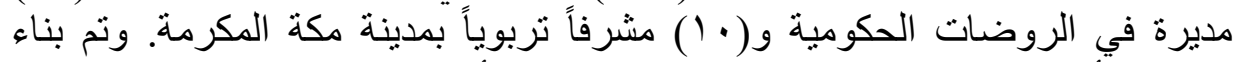

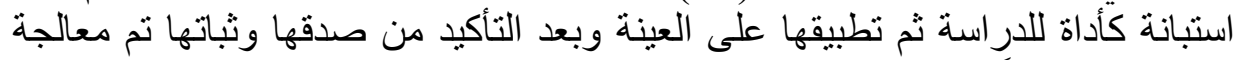
البيانات إحصائياً. توصل البحث إلى النتائج التالية : التيأ

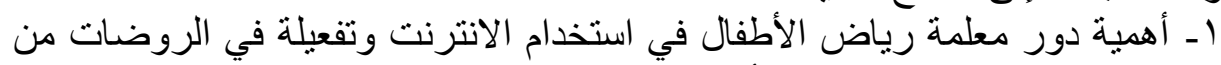

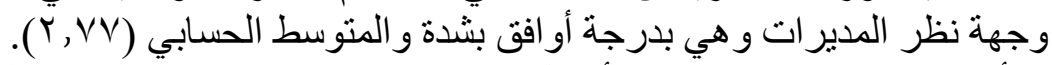

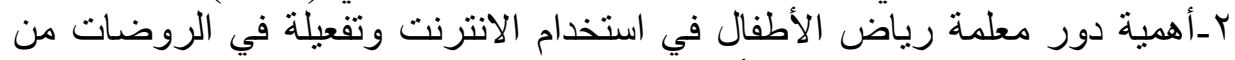

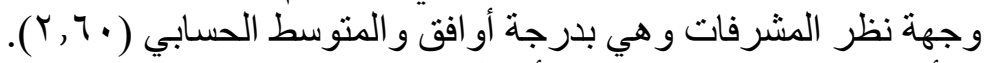

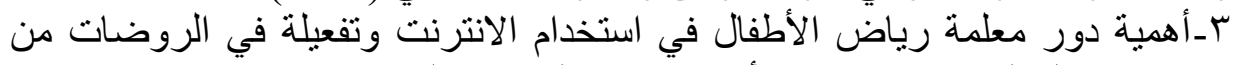

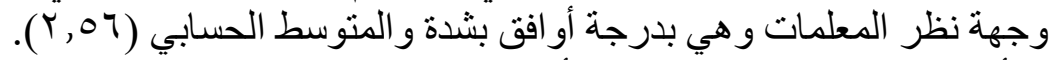

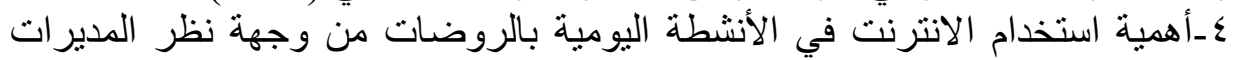

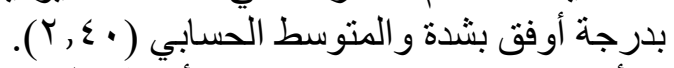

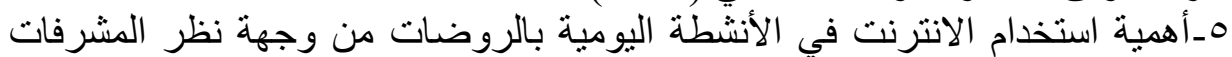

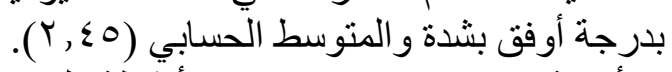

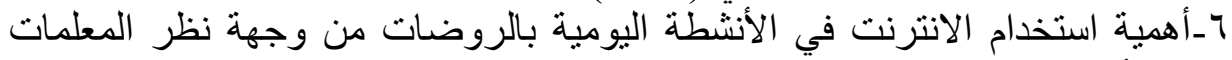

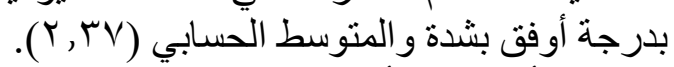

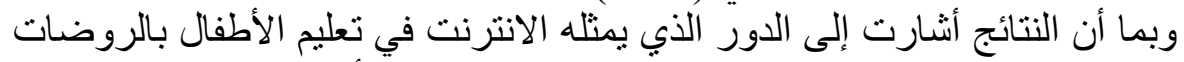

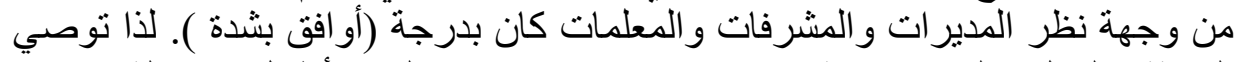

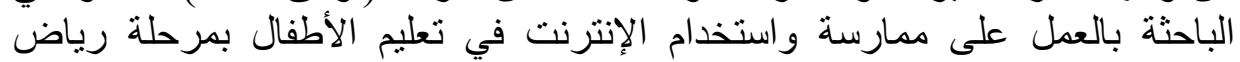
الأطفال.

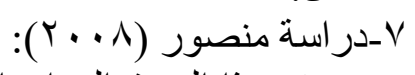

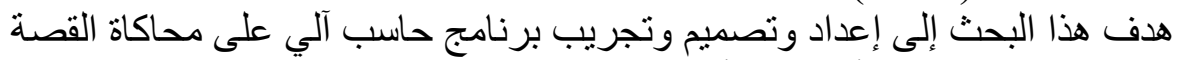
التفاعلية في تتمية القيم الأخلاقية لأطفال ما قبل المدرسة. تم تطبيق هذه البحث على على 


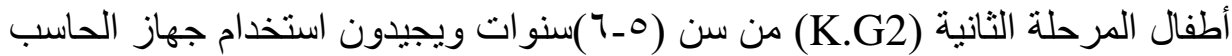

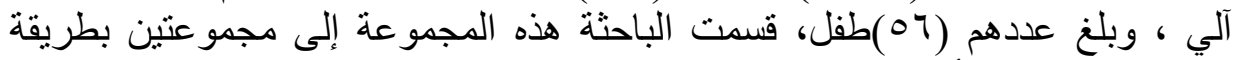

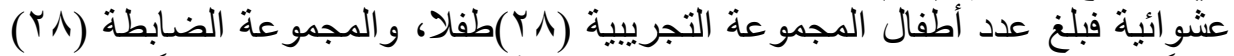

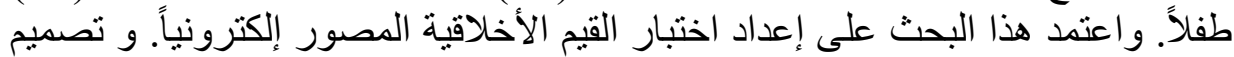

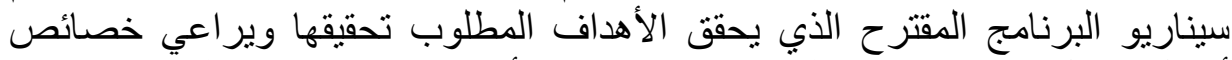
أطفال ما قبل المدرسة. وبعد التحقق من صلاحية التحفية الأدوات وتطبيقها على العينة توصل البحث الحالي إلى النتائج التالية :

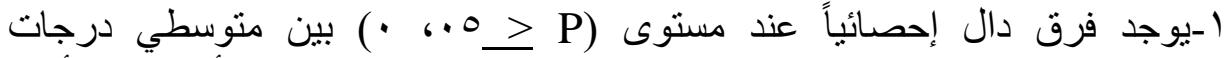

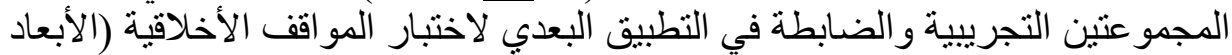

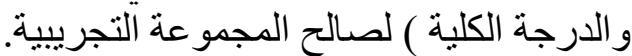

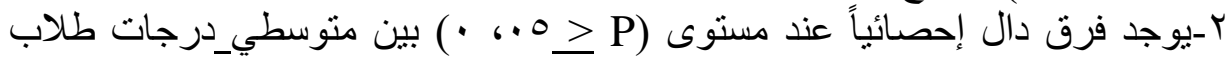

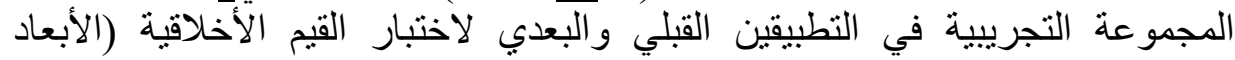

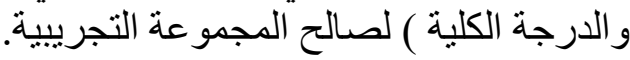

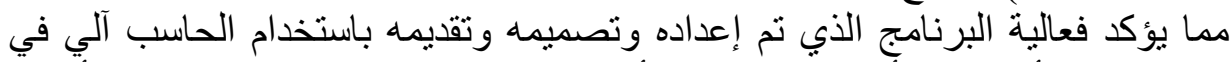
تنمية القيم الأخلاقية الأربع (الصدق، الأمانية الأنة، الإحترام، التعاون) لأى عينة الأطفال

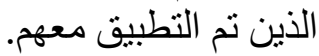

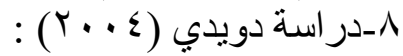

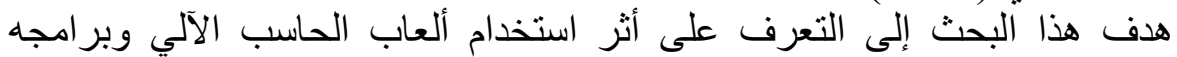

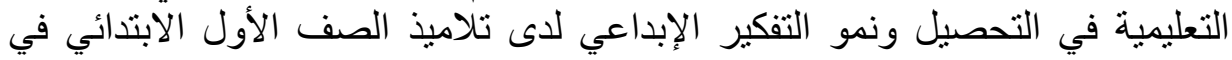

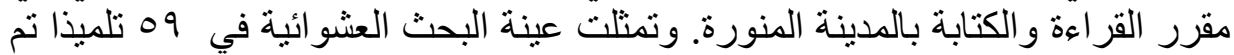

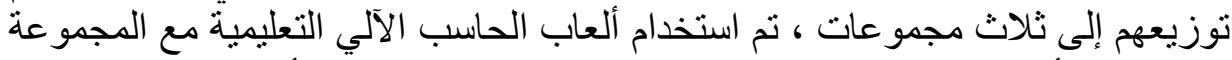

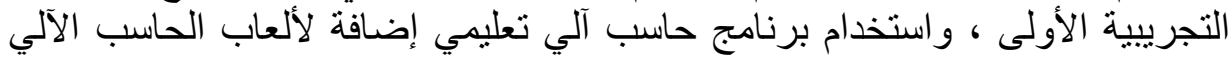

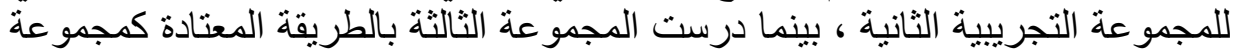

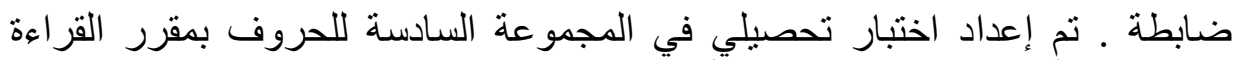

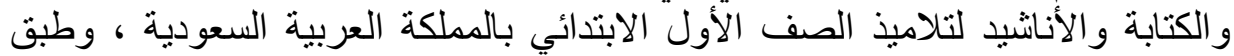

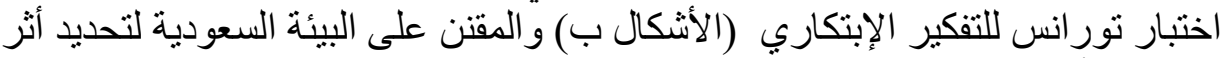

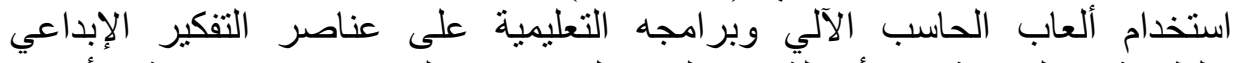

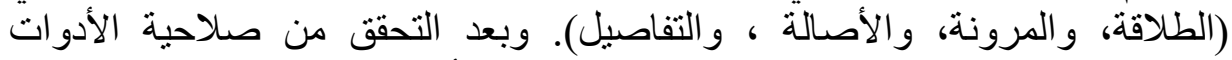

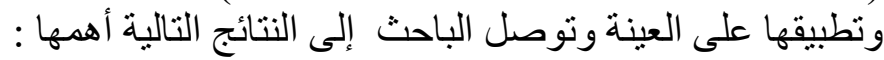

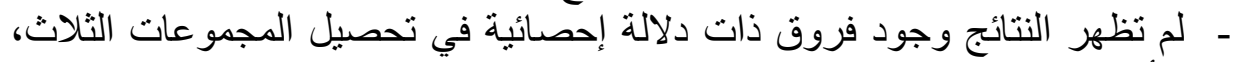

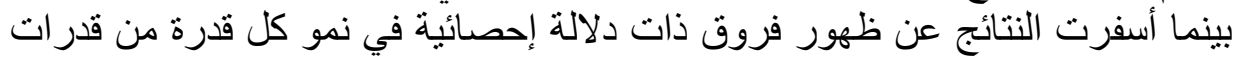

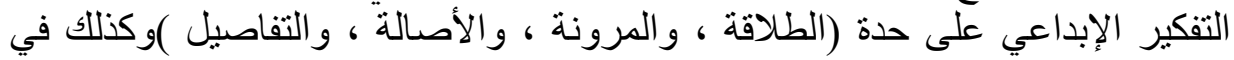


تتمية قدرة التفكير الإبداعي ككل لصالح المجموعة التجريبية الأولى والتي استخدمت ألعاب الحاسب الآلي التعليمية.

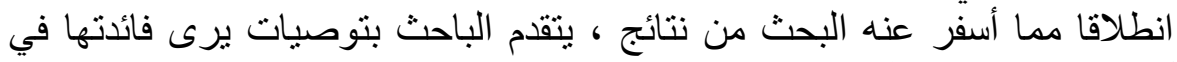
مجال استخدام التقنيات التعليمية في تنمية التفكير الإبداعي وهي التهي:

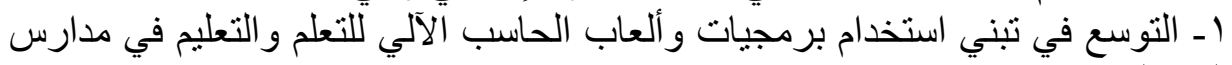
البرحلة الابتدائية

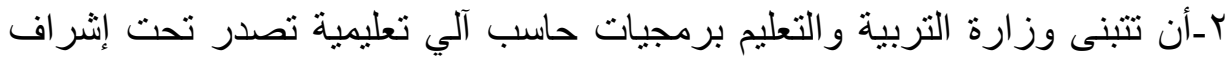

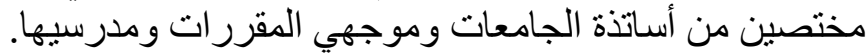

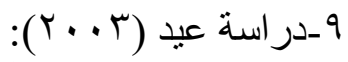

هدف هذا البحث إلى التعرف على على أثر استخدام الحاسب آلي في إكساب أطفال

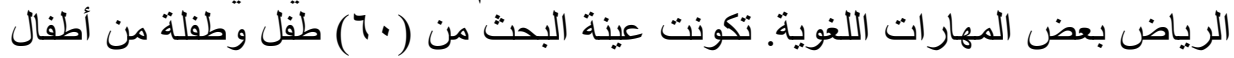

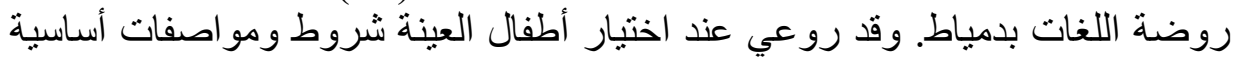

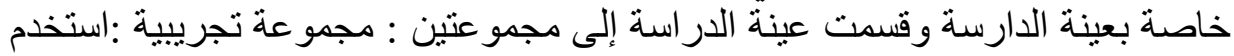

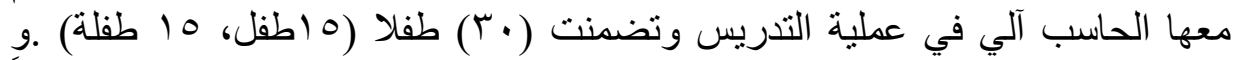

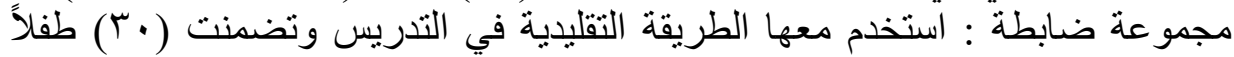

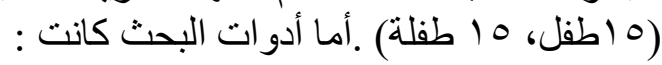

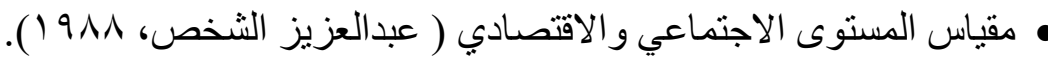

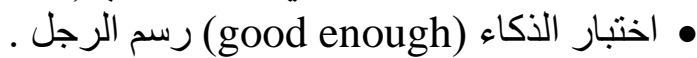

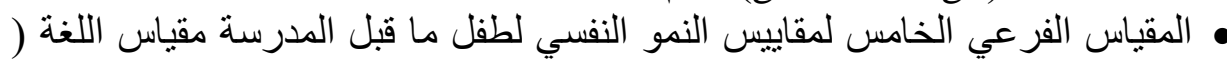

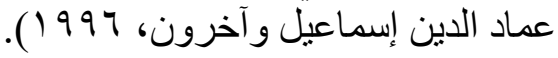

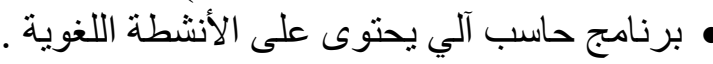

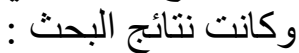
ا ـ تكافؤ مستوى المهارات اللغوية للأطفال في المجموعة التجريبية والمجموعة

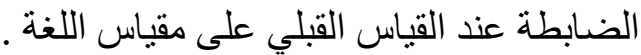

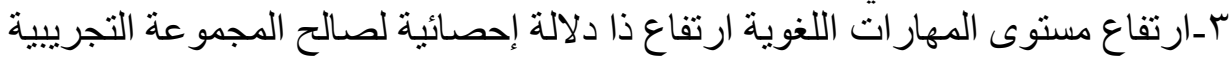

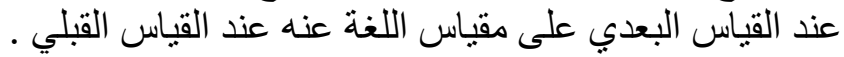

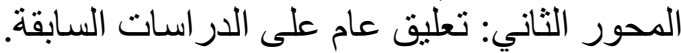

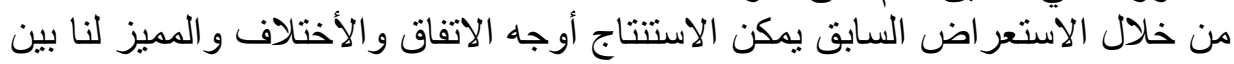

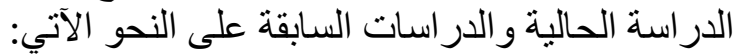

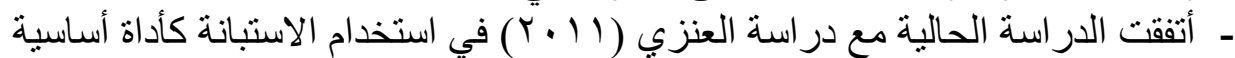

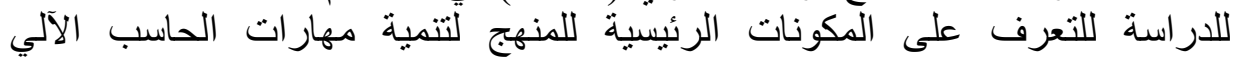


والأنترنت من وجهة نظر المتخصصين في مجال المناهج وطرق التدريس والحاسب

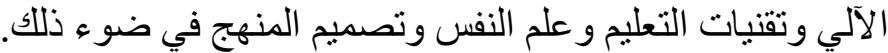

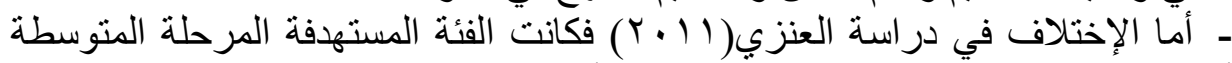

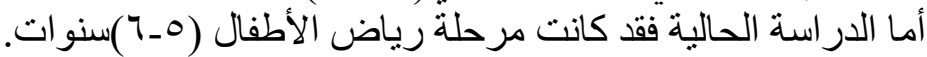

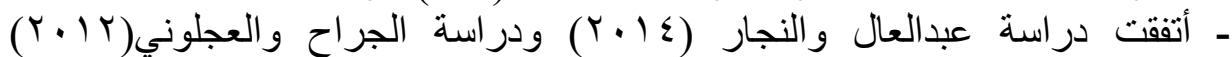

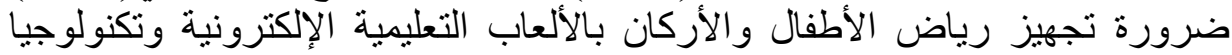

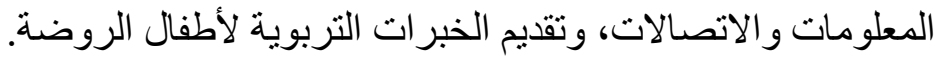

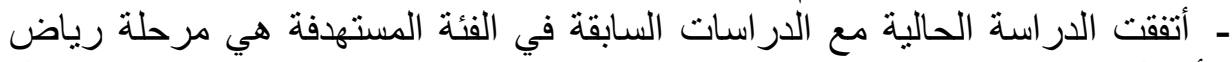

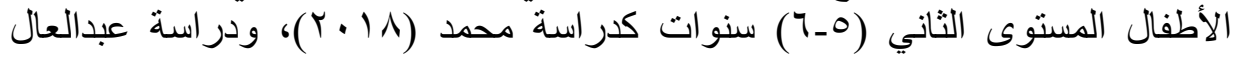

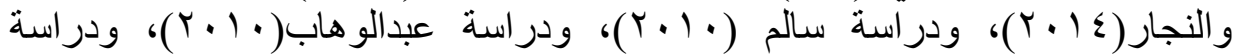

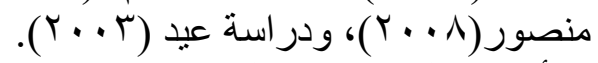

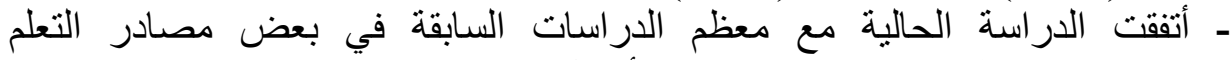

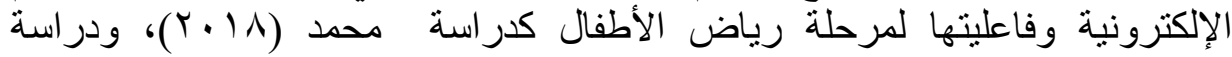

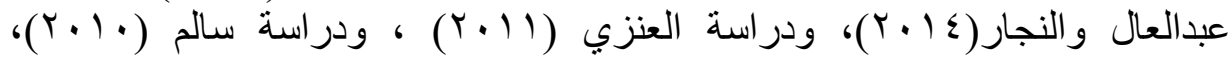

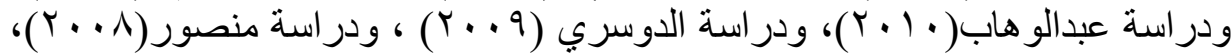

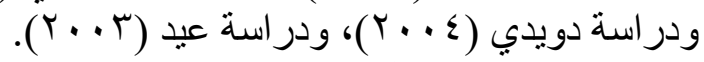

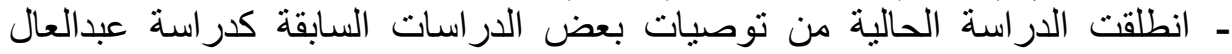

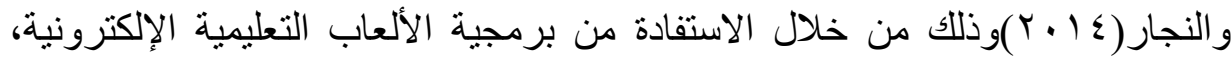

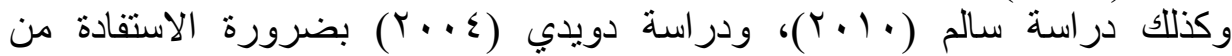
برمجيات و العاب الحاسب الآلي. - امتاز البحث في تصميم منهج لأطفال الروضة للابع التعامل مع مصادر التعلم الإلكترونية

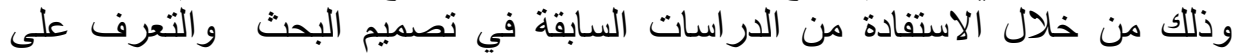

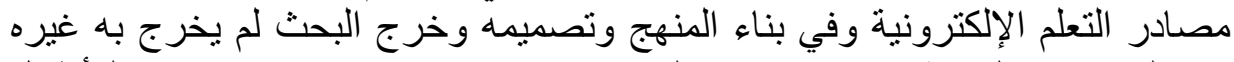

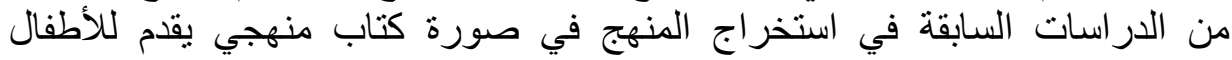
وتصميم وثيقة المنهج ودليل للمعلمة في كيفية تنفيذ الكتاب المنهجي. 
فيما يتعلق بتصميم منهج لأطفال الران الروضة للتعامل مع مصادر التعلم الإلكترونية في

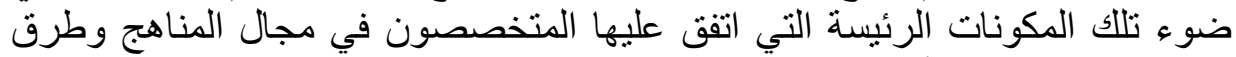
التدريس، ورياض الأطفال، وتقنيات التعليم والحاسب الآلي، جاءت التئ النتائج عن النحو

أو لاً: المكونات الرئيسة للمنهج :

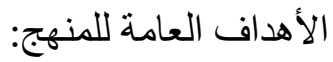
1 إكساب الطفل الثقة في التعامل مع مصادر التعلم الإلكترونية ؛ لمساعدته في حياته

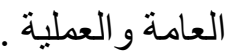
r _تتمية قدر ات ومهار العة ات الطفل؛ لاستخدام مصادر التعلم الإلكترونية.

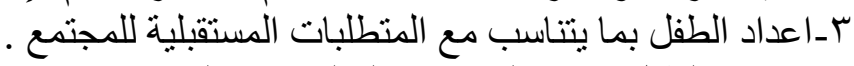

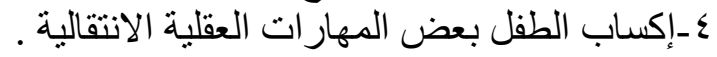

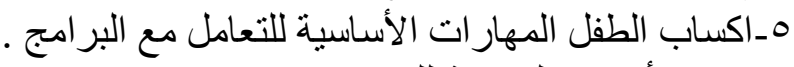

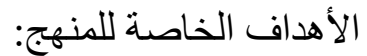

تتحدد الأهداف الخاصة للمنهج في إعداد الطفل ليصبح قادراً على التعامل مع :

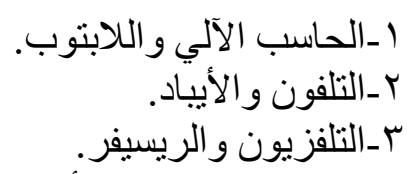
ع -وحدات التخزين ( الأقر اص الضوئية ، الفئناشئات ، الذواكر ، قارئ الذواكر ). هـالبلاي ستيشن( محطة الألعاب).

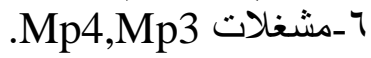
(Microsoft Word) (برنامج ^-1 برنامج (Microsoft Power Point). 9-برنامج( الرسام (Painter). • - أ - برنامج (متصفح الإنترنت (Internet explorer).

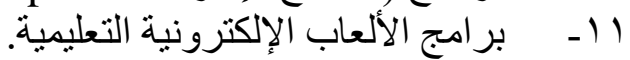

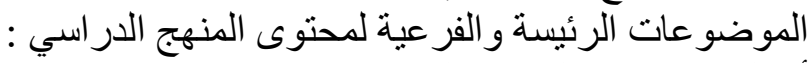

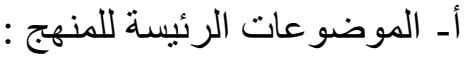


تم الاتفاق من قبل المحكمين عن (1) موضوعات رئيسة لمحتوى المنهج وهي كالآتي: - (الآن الموضوع عالأول : التعامل مع الحاسب الآلي و اللابتوب.

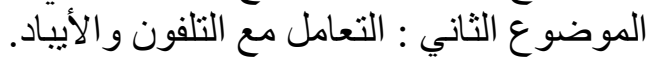

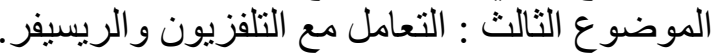

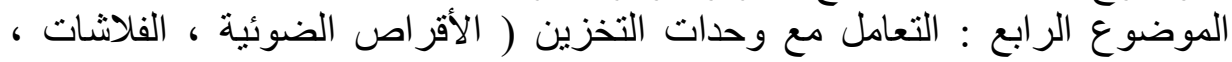

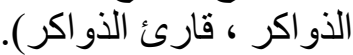
الموضوع الخامس: التعامل مع البلاي ستيثن الأن محطة الألعاب).

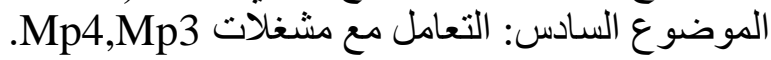

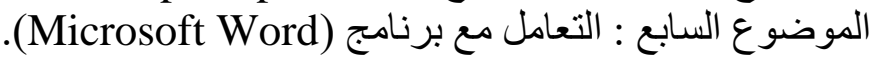

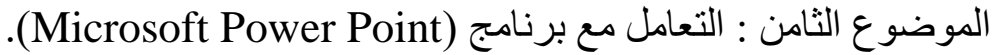

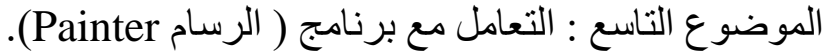

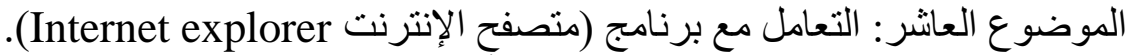

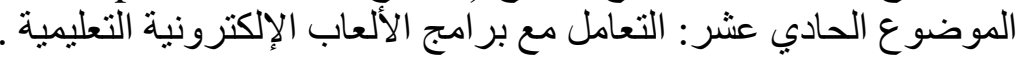

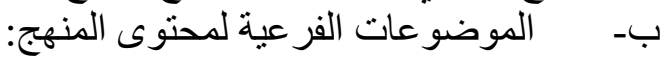

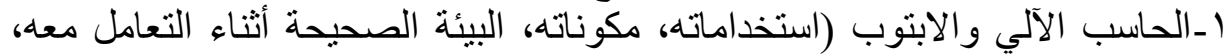

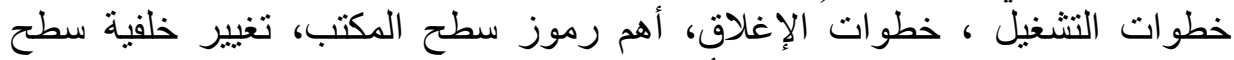

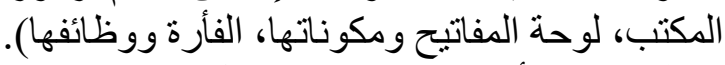

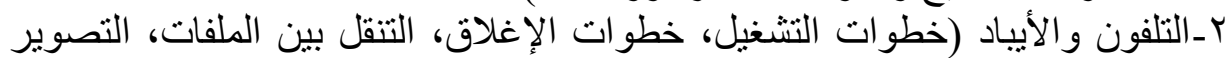

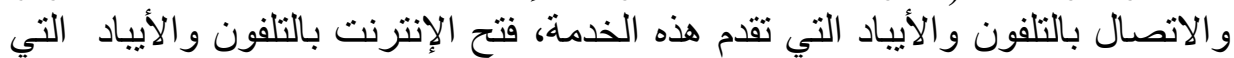
تقدم هذه الخدمة). بـالتلفزيون والريسيفر( خطوات التشغيل، خطوات الإغلاق، التنقل بين القنوات

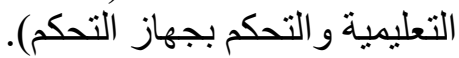
ع ـالبلاي ستيشن (خطو ات التشغيل ، خطوات التهات الإغلاق ، التتقل بين الألعاب و التحكم بجهاز التحكم ).

0-وحدات التخزين المختلفة( خطوات التشغيل، خطو ات الإغلاق ، التنقل بين ملفات)

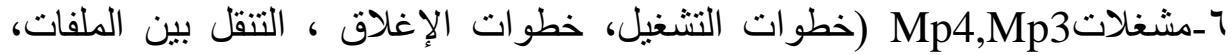

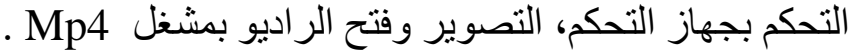
والبرنامج Microsoft Word(خطوات التشغيل، خطوات الإغلاق، واجهة البرنامج و الكتابة في البرنامج).

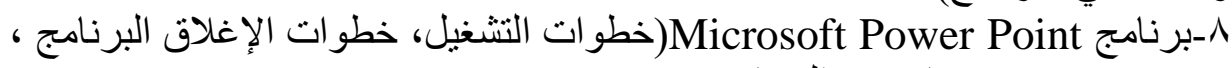
فتح عرض تقديمي سابق في البرنامج). 
9-برنامج الرسام Painter(خطوات التشغيل، خطوات الإغلاق ، واجهة البرنامج،

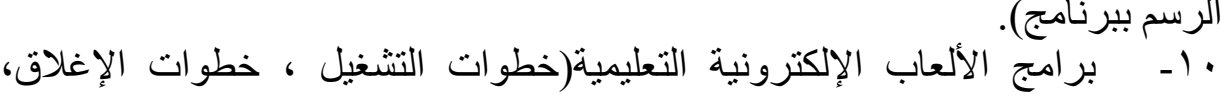
التنقل بين الملفات و التحكم بجهاز التحكم).

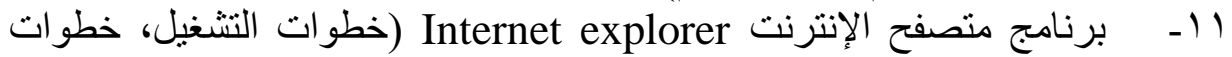

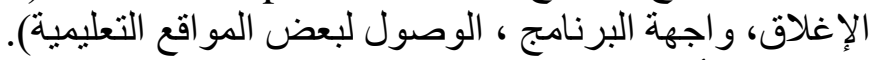

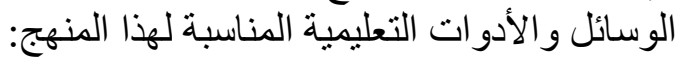

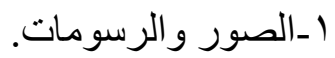

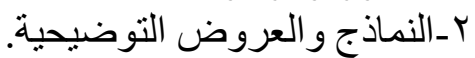
بـ الوسائل السمعية و البصرية الثنابتة والمتحركة والأفلام التعليمية و البرامج الحاسب

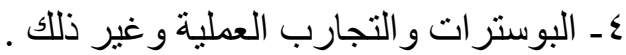

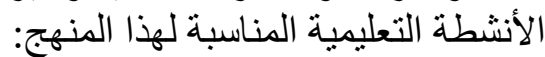
ا-عرض صور ونماذج عن الموضوعة التعات ، ومناقشتها مع الأطفال لاستخلاص المعلومات منها. Y_تكليف الأطفال بتنفيذ بعض مفردات المنهج تحت إثر اف الف المعلمة.

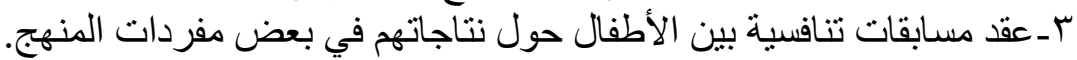

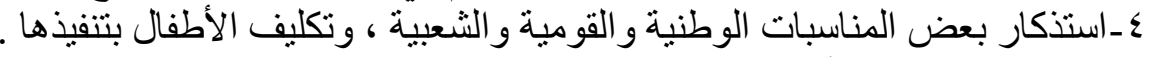

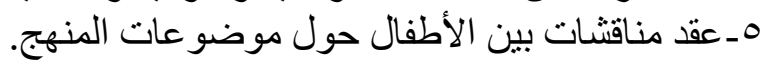

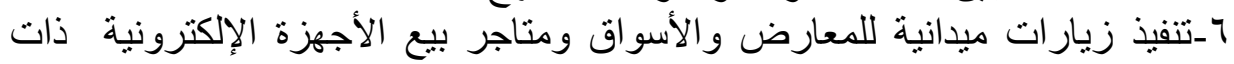

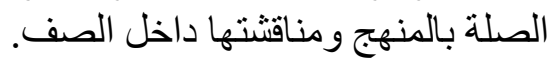
الطر ائق والاستراتيجيات المناسبة للاستخدام لتدريس أطفال الروضة والفئة وفن هذا المنهج (مصادر التعلم الإلكترونية):

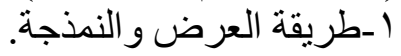

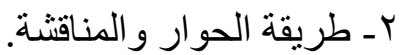
r- الاستقصاء و الاكتشاف. عـ - التعلم التعاوني. 0ـ التعلم بالملاحظة و التعاونية المحاكاة 7ـ التدريبات العملية. أساليب التقويم المناسبة لأطفال الروضة التبة وفق هذا المنهج:

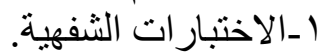
بـالاختبار ات التحررية " المصورة"ا 
آلية تقييم أداء( توزيع درجات) لأطفال الروضة في منهج (مصادر التعلم الإلكترونية): أـأعمال السنة:

$$
\begin{aligned}
& \text { - - أشتبار ات نظرية - شهرية. } \\
& \text { - - ' - أنشاط عملي أسبو عي. } \\
& \text { r- اختبار نصف العام: }
\end{aligned}
$$

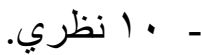

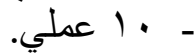

$$
\begin{aligned}
& \text { بـ الاختبار النهائي: }
\end{aligned}
$$

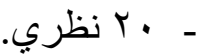

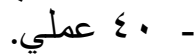

$$
\begin{aligned}
& \text { وأصبحت على النحو التالي : }
\end{aligned}
$$

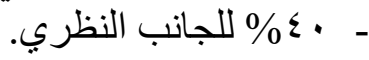

$$
\begin{aligned}
& \text { - - - }
\end{aligned}
$$

تقسيم الوقت اللازم لتدريس منهج( مصادر التعلم الإلكترونية لطفل الروضة) في

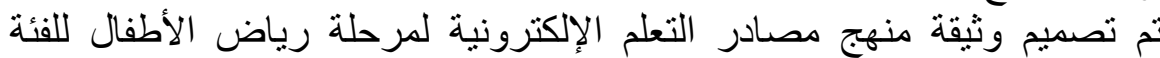
ثنانياً: وثيقة المنهُج.

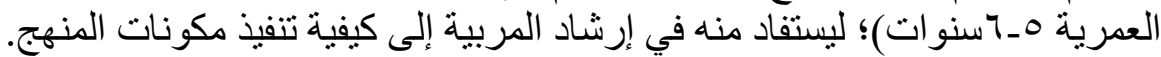

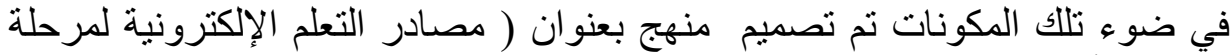

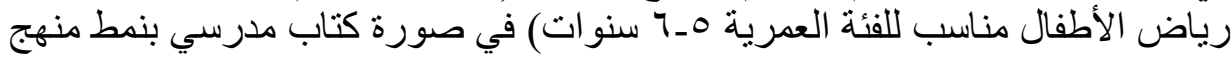

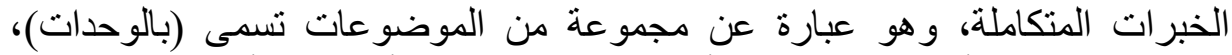

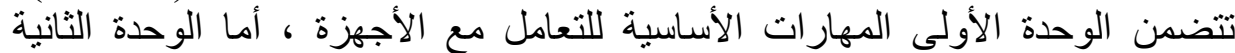

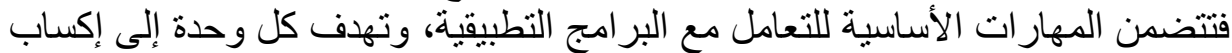

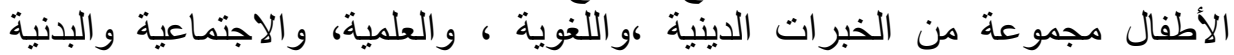

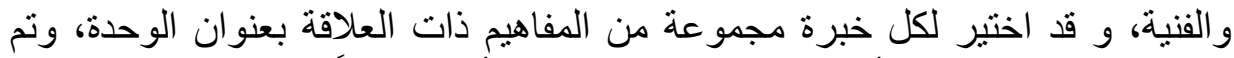

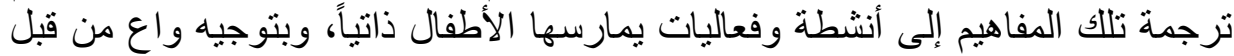


التوصبات: بناءً على النتائج التي تم التوصل البيها توصي الدراسة بالتالي:

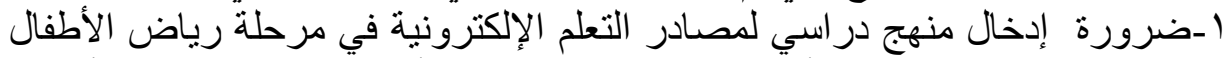

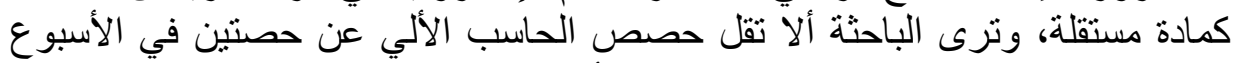

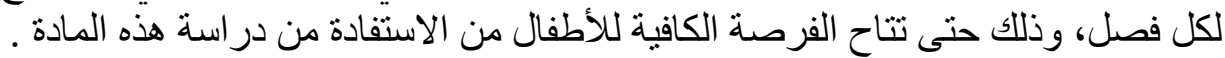

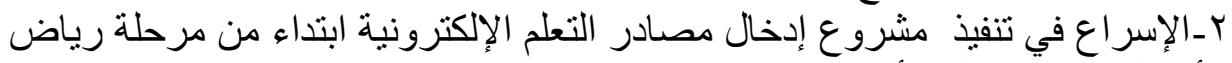

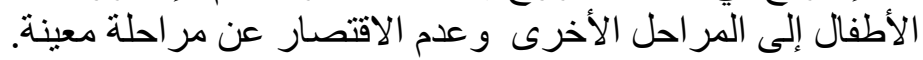

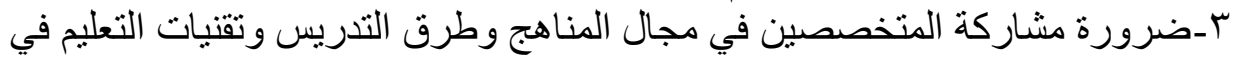

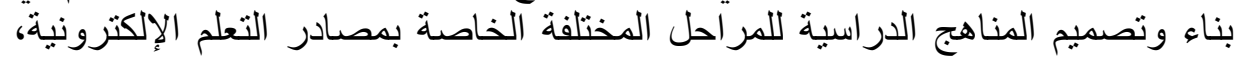

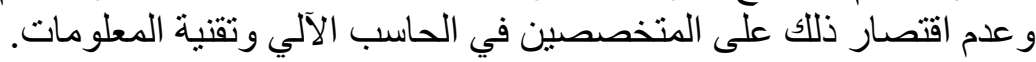

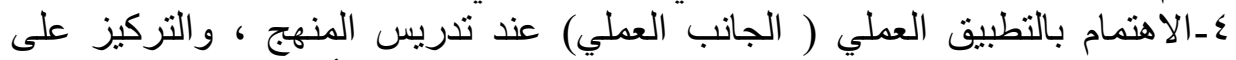

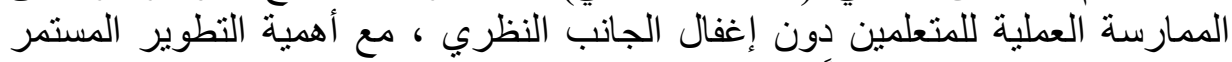

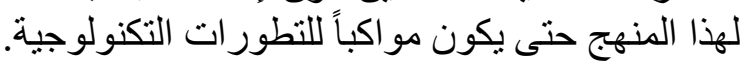

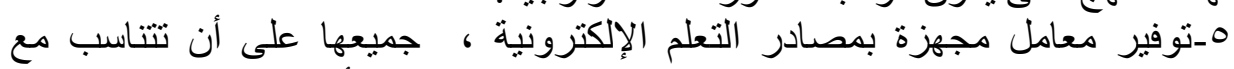

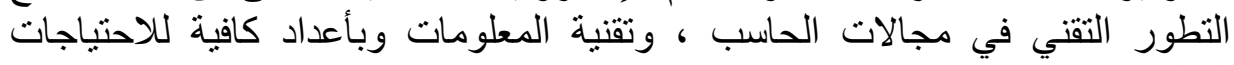
التعليمية. 7-توفير معلمين من ذوي الكفاءة والمقدرة ، و المؤهلين تأهيلاً كافياً يمكنهم من تدريس

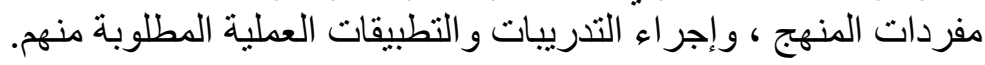




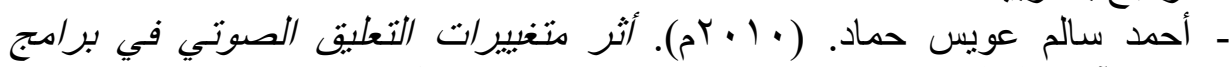

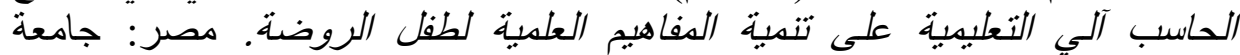

حلوان.كلية التربية.

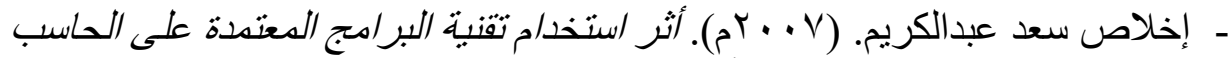

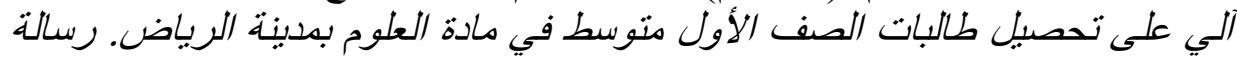

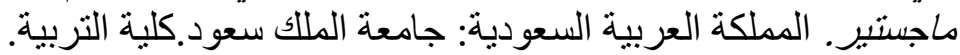

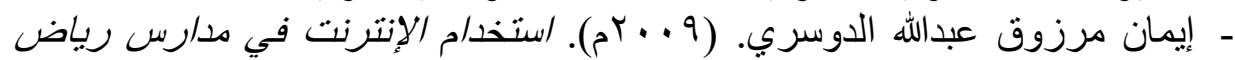

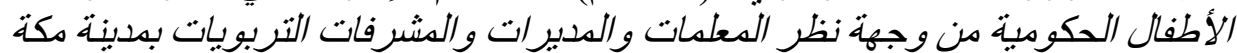

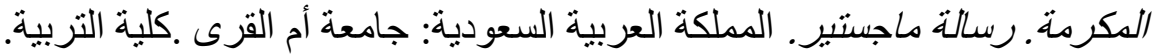

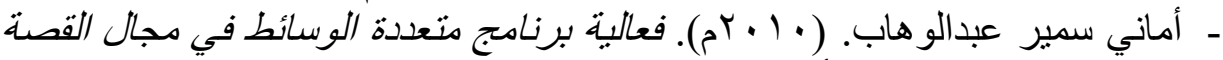

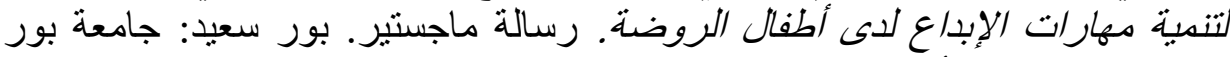
سعيد.كلية رياض الأطفال الأعال.

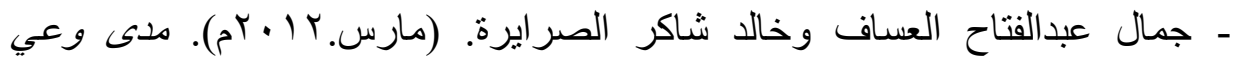

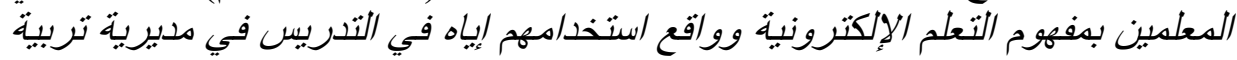

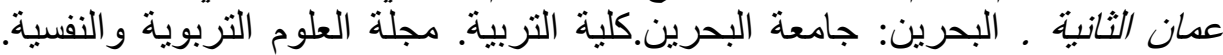

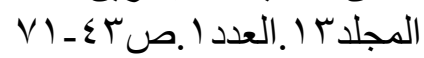

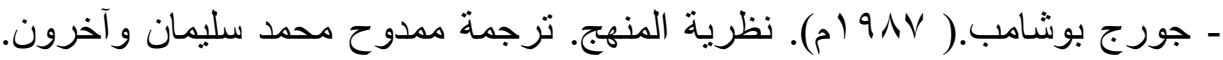
مصر.: الدار العربية للنشر و التوزيع.

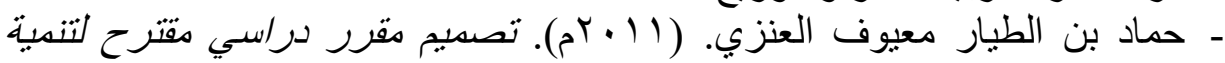

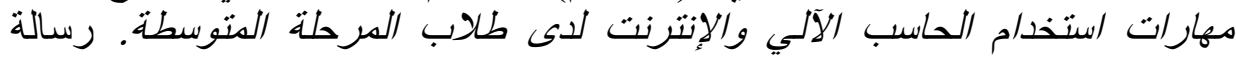

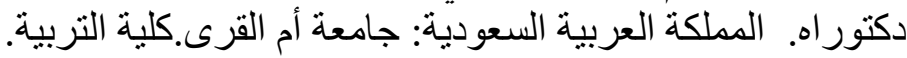

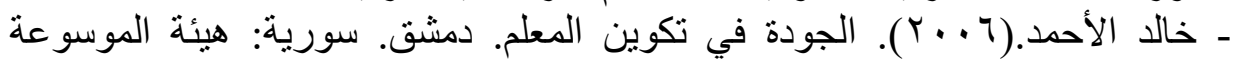

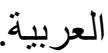

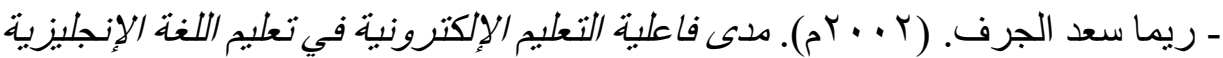

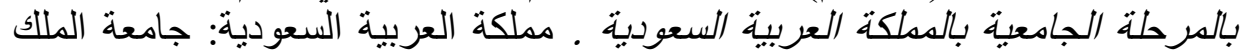

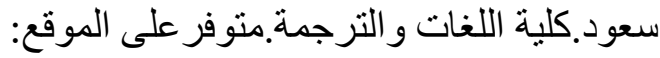
e-mail: reemasado@yahoo.com

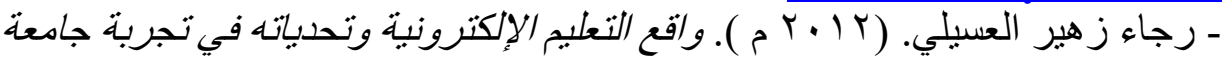

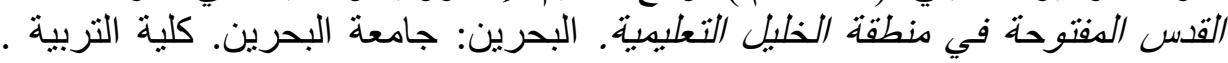

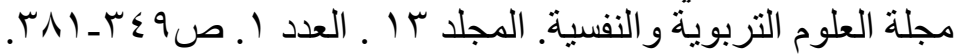




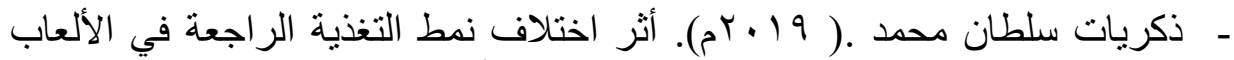

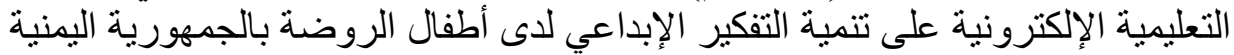

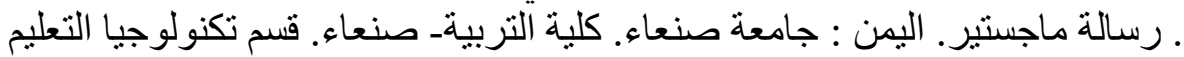

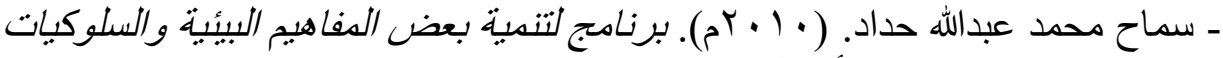
الإيجابية المرتبطة بها لدى أطفال الروضة بالجهمهورية البهنية. رسالة ماجستير . اليمن: جامعة صنعاء.كلية التربية.

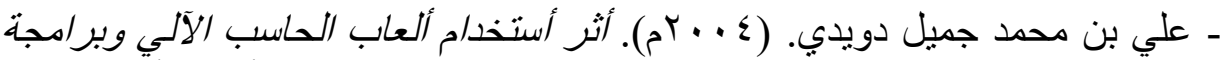

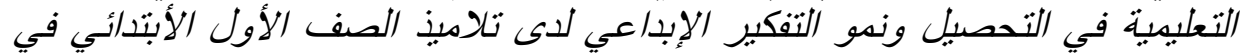

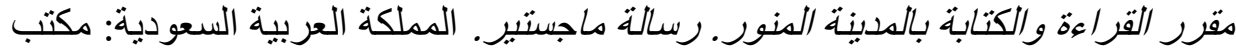
التربية العربي لدول الخليج.

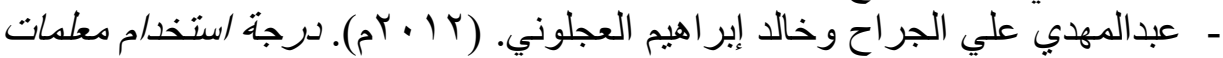

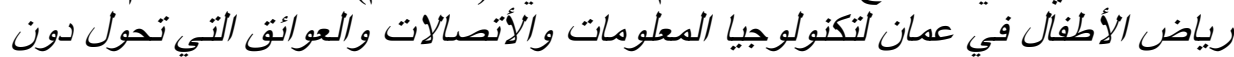

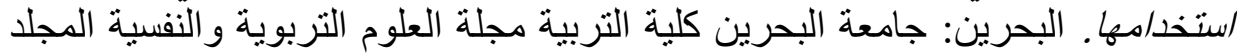

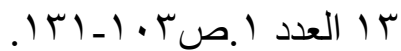

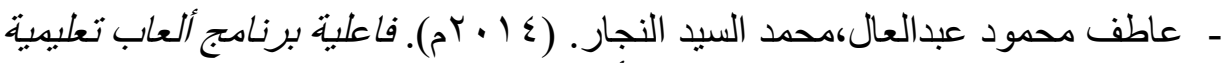

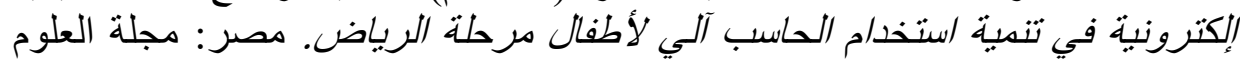

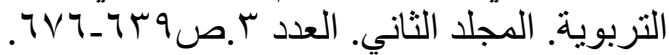

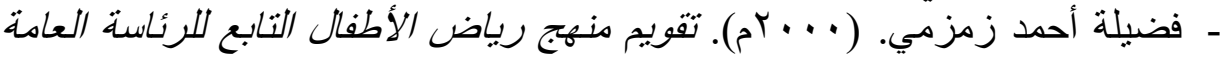

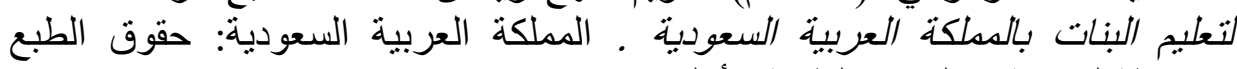

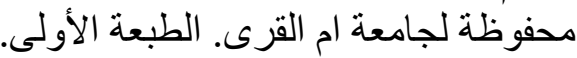

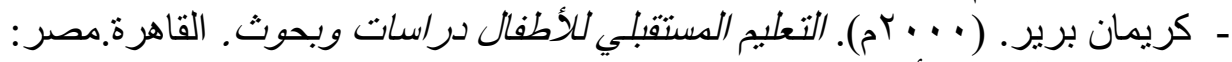
عالم المكتب.الطبعة الأولى. كوبر.

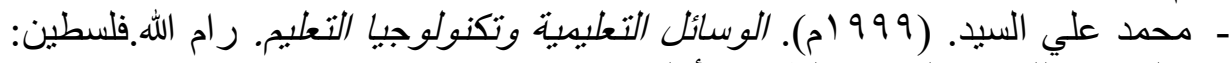

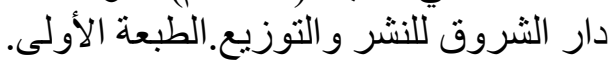

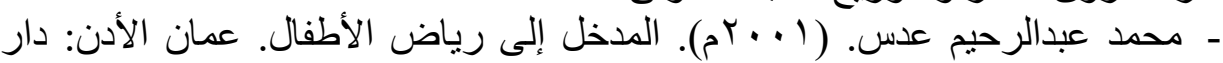
الفكر للطباعة والنشر و التوزيع. الطبعة الأولى.

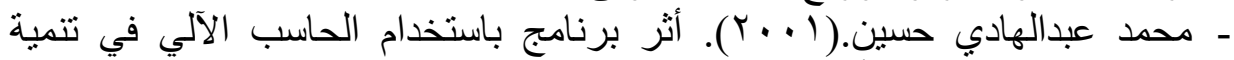

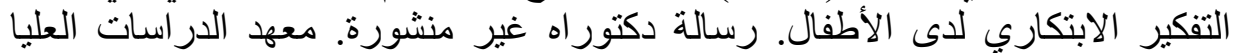

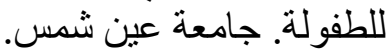

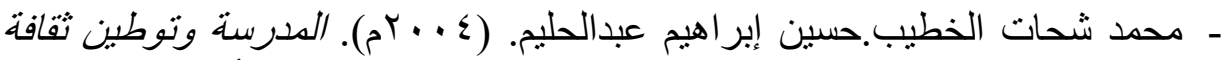

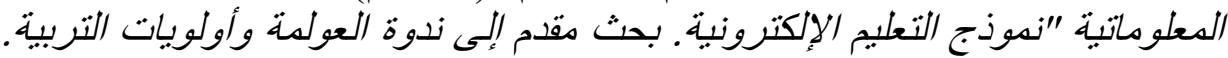

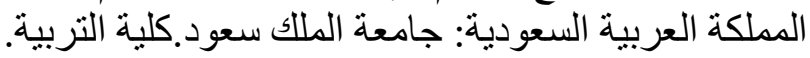




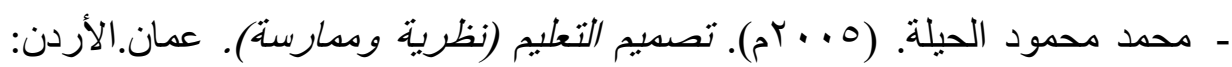
دار المسير. الطبعة الثالثة.

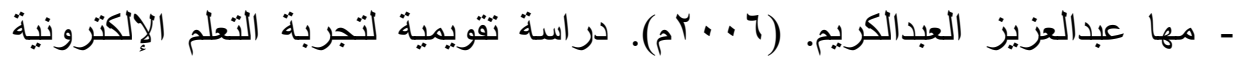

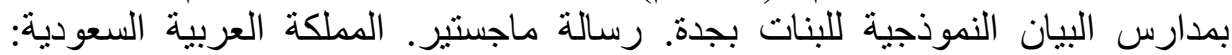
جامعة الملك سعود.

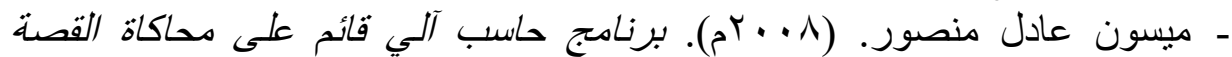

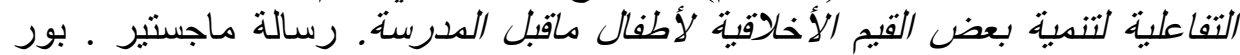

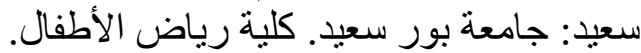

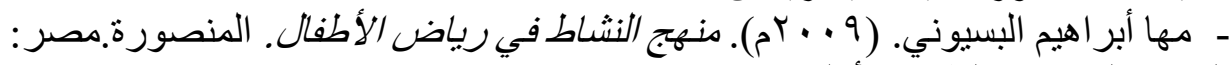
المكتبة المصرية.الطبعة الأولى.

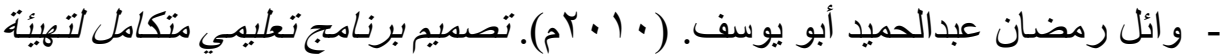

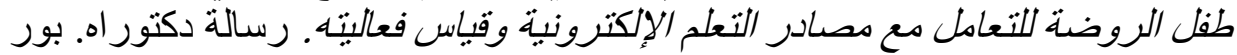

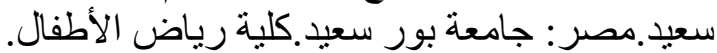

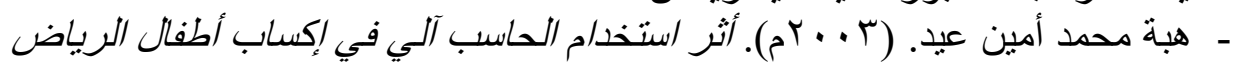

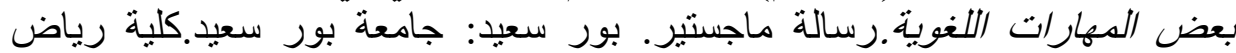

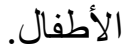

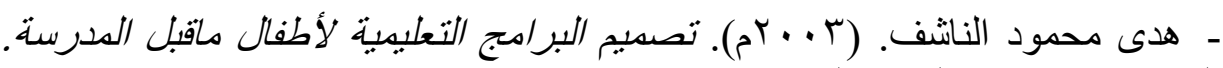
القاهرة.مصر: دار الكتاب الحديث. 
فاطمة قبيصي -د. .عزاللدين معاد

تصميم منهج لأطفال الروضة للتعامل ... 